\title{
Outcomes of hepatitis $C$ screening programs targeted at risk groups hidden in the general population: a systematic review
}

\author{
Freke R Zuure ${ }^{1 * \dagger}$, Anouk T Urbanus ${ }^{1,2+}$, Miranda W Langendam³ ${ }^{3}$ Charles W Helsper ${ }^{4}$, \\ Charlotte HSB van den Berg ${ }^{1,2}$, Udi Davidovich ${ }^{1}$ and Maria Prins ${ }^{1,2}$
}

\begin{abstract}
Background: Effective screening programs are urgently needed to provide undiagnosed hepatitis $C$ virus (HCV)-infected individuals with therapy. This systematic review of characteristics and outcomes of screening programs for HCV focuses on strategies to identify HCV risk groups hidden in the general population.

Methods: We conducted a comprehensive search of MEDLINE and EMBASE databases for articles published between 1991-2010, including studies that screened the general population using either a newly developed (nonintegrated) screening program or one integrated in existing health care facilities. Look-back studies, prevalence studies, and programs targeting high-risk groups in care (e.g., current drug users) were excluded.

Results: After reviewing 7052 studies, we identified 67 screening programs: 24 nonintegrated; 41 programs integrated in a variety of health care facilities (e.g., general practitioner); and 2 programs with both integrated and nonintegrated strategies. Together, these programs identified approximately 25,700 HCV-infected individuals. In general, higher HCV prevalence was found in programs in countries with intermediate to high HCV prevalence, in psychiatric clinics, and in programs that used a prescreening selection based on HCV risk factors. Only 6 programs used a comparison group for evaluation purposes, and 1 program used theory about effective promotion for screening. Comparison of the programs and their effectiveness was hampered by lack of reported data on program characteristics, clinical follow-up, and type of diagnostic test.
\end{abstract}

Conclusions: A prescreening selection based on risk factors can increase the efficiency of screening in low-prevalence populations, and we need programs with comparison groups to evaluate effectiveness. Also, program characteristics such as type of diagnostic test, screening uptake, and clinical outcomes should be reported systematically.

Keywords: HCV, Testing, Case finding, Case detection, Reporting guidelines

\section{Background}

Hepatitis C virus (HCV) infection, primarily a blood-borne virus and first identified in 1989, is a major public health problem. Worldwide an estimated 130-170 million individuals are $\mathrm{HCV}$-antibody positive [1], of whom approximately $75 \%$ are chronically infected and at risk for the development of cirrhosis, which can lead to liver cancer and death [2,3]. In chronically infected patients, the onset of $\mathrm{HCV}$ infection

\footnotetext{
* Correspondence: fzuure@ggd.amsterdam.nl

${ }^{\dagger}$ Equal contributors

'Public Health Service of Amsterdam, the Netherlands, Infectious Diseases Cluster, P.O. Box 2200, Amsterdam 1000 CE, The Netherlands

Full list of author information is available at the end of the article
}

and the development of cirrhosis are usually asymptomatic [2,4]; many infections remain undetected or are diagnosed at a late stage. In the United States of America (USA), an estimated $43 \%$ to $72 \%$ of $\mathrm{HCV}$ infections are undiagnosed [5-7]. In 2001, successful combination therapy for HCV became widely accessible $[8,9]$ and more effective therapeutic options are becoming available [10,11]. Effective screening programs are urgently needed to provide undiagnosed HCV-infected individuals with therapy and to spread information about preventive measures that each person should take, thus decreasing future morbidity and mortality.

There are several types of screening strategies such as mass population screening, selective screening, or case

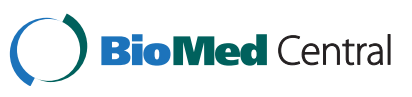


finding (i.e., opportunistic screening [12]). Selective screening of risk groups for HCV (see below) has been recommended $[13,14]$. Some of the high risk groups for $\mathrm{HCV}$ are relatively easy to reach and have been targeted by screening programs as part of specialized medical care (e.g., current drug users (DUs) on methadone treatment who have injected drugs in the past [15], hemophiliacs [16], and HIV-infected individuals receiving clinical care [17]). However, other risk groups are more difficult to target for screening. For example, persons at risk for $\mathrm{HCV}$ infection through occasional injecting drug use (IDU) in the remote past will not attend programs targeted at active injecting drug users and might not identify themselves as being at risk for HCV infection. The same holds true for individuals who received a blood transfusion before 1992. These groups can be considered as 'hidden risk groups' among the general population. The size of this hidden population may be substantial. A recent study estimated that of the total population of $\mathrm{HCV}$-infected individuals in a highincome country, only $34 \%$ are in relatively easy to reach high-risk groups such as hemophiliac patients, HIVinfected patients, and persons with a history of IDU; $41 \%$ are first-generation migrants and $25 \%$ belong to other risk groups [18].

\section{Risk groups for HCV infection $[13,14]$}

- Individuals with a history of injecting drug use (IDU), including those who injected only a limited number of times many years ago and do not consider themselves to be drug users

- Individuals who received clotting factor concentrates produced before 1987 or a blood transfusion or an organ transplant before 1992 including hemophiliac patients (systematic screening of blood donors for HCV antibodies was introduced in 1991) [19]

- Individuals with occupational exposure to infected blood

- People living with HIV

- Chronic hemodialysis patients

- Children born to HCV-infected mothers

- Individuals exposed to HCV-infected blood through invasive procedures or blood product transfusions due to absence of precautionary measures to prevent transmission, mostly in low-resource settings. This group includes first-generation migrants.

Finding an effective strategy to identify the hidden population of undiagnosed $\mathrm{HCV}$-infected individuals is challenging. An overview of HCV screening programs provides insight into strategies that have been used so far and their outcomes, and can provide insight into the best way forward. In our review, we systematically evaluate characteristics and outcomes of $\mathrm{HCV}$ screening programs targeted at risk groups hidden in the general population. We focused in particular on the promotion of the screening program, whether or not prescreening selection criteria were used, and the use of psychosocial theory or knowledge about determinants facilitating participation in screening programs, since health promotion programs that are based on theory are more likely to be effective than those that are not [20]. We discuss the implications of these findings for future $\mathrm{HCV}$ screening strategies.

\section{Methods}

\section{Search strategy}

We searched in the MEDLINE (PubMed) and EMBASE databases for articles published in any language before July 27,2010 . A comprehensive strategy was used to include all possible studies in which individuals were screened for HCV. Search terms included hepatitis C (Medical Subject Headings [MeSH] for PubMed and Explosion search [Exp] for Embase) or HCV or "hepatitis C" in title or abstract combined with search terms in title or abstract that reflect screening (i.e., mass screening [MeSH/Exp], screen", "case finding"", "case identification"", "case detection", "hepatitis $\mathrm{C}$ testing", "HCV testing") or search terms in title or abstract and/or $\mathrm{MeSH} / \mathrm{Exp}$ that reflect campaigns or evaluation of health programs (i.e., campaign*, health promotion, health service"”, feasibility, pilot", "program" evaluation"”, "program" effect", ""health care quality"). The search was limited to articles published after 1990 since a more sensitive second-generation HCV antibody test was introduced in 1991 [21]. The complete search strategy including truncation characters is available from the authors. In addition, we screened the reference lists of the articles that were included in the selection.

\section{Study selection}

Studies were included if they reported screening of individuals in the general population, including screening in primary care facilities that are not related to specific $\mathrm{HCV}$ risk groups. Screening is defined as testing for HCV antibodies. Exclusion criteria included 'look-back' studies, in which recipients of $\mathrm{HCV}$-infected donor blood are notified and offered screening and studies conducted in specific, identifiable risk groups for $\mathrm{HCV}$ that are in specialized care: injecting drug users, HIV-infected individuals, incarcerated individuals, hemodialysis patients, or multitransfused patients such as hemophiliac patients. In addition, studies were excluded if 1 ) the study was designed to assess the prevalence in a given population, and/or 2) if the study was undertaken to investigate transmission rates and determinants or the association between $\mathrm{HCV}$ infection and another medical condition, and/or 3) nothing was reported about notification, referral, or medical follow-up of 
participants (these studies were considered prevalence studies, not aiming to identify HCV infections). The latter criterion did not apply to studies describing HCV screening at the general practitioner (GP) clinic, since notification of results in this setting is considered to take place. Articles in languages other than English, Dutch, French, German, or Spanish were excluded if there was no English abstract of if the English abstract did not yield enough data.

The first selection round was based on title and abstract (if available) only and was done by four authors (FZ, AU, $\mathrm{CH}$, and $\mathrm{CvdB}$ ). The database including the titles and abstracts obtained through the search was split in four. The reviewers independently screened two of the subdatabases each so that each title/abstract was screened in duplicate. Studies were included in the second screening round if selected by at least one reviewer. The second selection round comprised screening of the full-text articles. Two authors (FZ and AU) independently screened all articles for eligibility using the aforementioned criteria. Any discrepancies were resolved by discussion until consensus was reached, and unresolved discrepancies were arbitrated by a third reviewer (MP).

\section{Data extraction and validity checking}

Data regarding program characteristics and program outcomes (see Parameters of screening programs) were extracted and cross-checked by two reviewers (FZ and AU). If the study reported $\mathrm{HCV}$ prevalence, but without specifying whether it concerned $\mathrm{HCV}$-antibody or HCVRNA prevalence, and if information about the test that was used was lacking, we assumed it to be HCVantibody prevalence. Since the studies were performed in different periods of time, different types of tests were used over the years. Therefore the prevalences were qualified depending on the test used. Anti-HCV and HCV-RNA prevalence rates of studies were considered suboptimal 1) if data was collected prior to 1994 when sensitivity and specificity of tests were not optimal $[19,22]$ or 2) if studies did not confirm reactive $\mathrm{HCV}$ antibody test results by immunoblot or PCR to eliminate false positives. Tests were considered valid if performed after 1993 and if 1) second- or higher-generation immunoblot assays from Ortho, Chiron, Novartis (RIBA), Innogenetics (LiaTek), Pasteur (DECISCAN HCV), Genelabs Diagnostics (HCV BLOT), or Mikrogen (recomBlot HCV IgG 2.0) were used to confirm HCV antibody reactive results or 2) PCR was used to confirm HCV-antibody reactive results. The validity of outcomes of studies that did not indicate which test was used, and studies that used dried blood spot (DBS), oral fluid screening, or immunoblot assays different from those indicated above, was considered undecided.

We distinguished two types of settings and presented the screening programs according to these: integrated and nonintegrated screening. Integrated screening refers to programs that are integrated within already existing health care facilities, whereas in nonintegrated screening, the program is exclusively set up for the screening. In addition, since screening strategies may differ according to the HCV prevalence in a specific country, data are presented not only by the type of setting, but also separately for low $\mathrm{HCV}$ prevalence $(\leq 2 \%))$ and intermediate to high HCV-prevalence countries ( $>2 \%$; countryspecific prevalence estimates were obtained from reference [23]).

\section{Parameters of screening programs}

Program characteristics

- Country (and region, if applicable) of the study

- Estimated HCV antibody prevalence in the country

- Calendar year(s) of data collection

- Duration of enrolment/screening period

- Setting (i.e., whether HCV screening was integrated within already existing health care facilities or whether the program was exclusively set up for the screening [i.e., nonintegrated screening])

- Use of psychosocial theory or previous research findings as a basis for communicating the screening and for stimulating screening uptake

- Size of the targeted population

- Use of media activities and/or personal invitations to promote screening

- Use of screening criteria based on HCV risk factors

- Incentive or participant's costs for screening

- Anonymous or nonanonymous participation

- Type of HCV test(s) that was used for screening

- Screening for other diseases performed

- Use of a comparison group for evaluation purposes

Program outcomes

- Response rate (i.e., proportion of the target population that was screened)

- Number of participants (i.e., number of individuals that were screened)

- Number of HCV cases identified

- Number of HCV cases already known

- HCV-antibody prevalence

- Risk profile of identified cases

- Proportion of HCV-antibody positives with detectable HCV RNA

- Number of referrals to specialist

- Start and outcomes of treatment

\section{Results}

The search strategy identified 5,263 records from the MEDLINE database and 6,300 from the EMBASE database. After duplicates were eliminated, 7,052 of 11,563 records remained. Of those, 737 were selected as potentially 
relevant to the review, and full-text articles were retrieved and reviewed independently in duplicate. We excluded 677 articles; 652 articles because they did not meet the inclusion criteria (the majority because they were prevalence studies, or studies that only reported statements about HCV screening guidelines and policy, not including any screening results), and 3 Japanese articles and 1 Italian because they did not provide an English abstract. In addition, 20 articles (two Chinese [24,25], eight Japanese [26-33], one Icelandic [34], four Russian [35-38], two Turkish $[39,40]$, one Czech [41], and two Taiwanese [42,43]) seemed relevant on the basis of the English abstracts, but were excluded as the abstracts alone did not yield enough information for review. One article was excluded because the same data were reported in two papers $[44,45]$. Of the 60 studies remaining, references lists were screened yielding an additional 106 potentially relevant records. The full-text articles were retrieved and screened independently in duplicate, and 7 of the 106 studies were selected for inclusion. In total, 67 studies remained in the final selection.

The 67 studies identified were done in the USA $(n=27)$, Europe $(n=27$; mostly France and the United Kingdom $[\mathrm{UK}])$, Asia $(\mathrm{n}=4)$, Australia $(\mathrm{n}=4)$, South America $(\mathrm{n}=3)$, Egypt $(\mathrm{n}=1)$ and Saudi Arabia $(\mathrm{n}=1)$. We identified 24 nonintegrated and 41 integrated studies, plus two studies that used both strategies (the latter are shown in the paragraph below for the results of the nonintegrated part of their program, and in the subsequent paragraphs for the results of the integrated part of their program) $[46,47]$. A total of $85 \%(22 / 26)$ of the nonintegrated programs and all of the integrated programs were from low $\mathrm{HCV}$-prevalence countries.

\section{Nonintegrated HCV screening programs in low HCV- prevalence countries $(n=22)$ \\ Program characteristics}

Additional file 1: Table S1 presents the 20 nonintegrated $\mathrm{HCV}$ screening programs and the 2 programs that combined an integrated and non-integrated screening approach that were performed in low HCV prevalence countries. In total, 12 of the 22 programs were carried out in the USA. The table is sorted by population type; seven studies were aimed at screening the general population; the other 15 studies targeted specific groups in which a higher HCV prevalence might have been expected (e.g., migrants, homeless individuals, firefighters, surgeons). Five of the 22 programs reported the use of personal screening invitations either face to face or by mail, and 12 reported the use of media activities to attract individuals for screening. Eight studies reported the possibility for individuals to participate anonymously. Only nine of 22 studies reported the costs for participants to be screened; in all of them, screening was offered free of cost, and one study offered a t-shirt as an incentive for screening [48].

With respect to screening procedures, except for two, all programs used venipuncture to collect serum. A program targeted at firefighters [49] used home specimen collection kits for serum collection. A program targeted at migrants [46] initially used oral fluid HCV antibody tests followed by a blood test for those who tested positive (no further details reported). In the majority $(16 / 22)$ of the programs, participants were also screened for other infections (mostly HIV and hepatitis B virus $[\mathrm{HBV}]$ ) or elevated liver enzymes (alanine aminotransferase [ALT], aspartate aminotransferase [AST]).

\section{Program outcomes}

The number of individuals screened for HCV antibodies per program ranged from 19 to 8,650 . The screening uptake was reported in 13/22 studies, and varied from $>20 \%$ in a screening program at a local health fair in the USA [50] to $100 \%$ in a program that used household visits to identify transfusion recipients and invite them for screening in Cuba [51]. The HCV prevalence varied from $0 \%$ to $28.3 \%$. The latter was found in a community-based screening program in New York City targeted at migrants from the former Sovjet Union. HCV risk-profile data were available for only a subset of the HCV-infected individuals in that study and included intramuscular injections and blood transfusions. Some of the programs among a so-called 'general population' (see Additional file 1: Table S1, row 1-7) that found relatively high HCV prevalences (e.g., 10.5\% in a walk-in clinic [52]), did not collect risk profile data of their participants, limiting the interpretability of their findings. Two of 22 studies used a prescreening risk assessment in order to limit screening to those with established HCV risk factors: one did not report the prevalence nor screening uptake [53]; the study in Cuba reported the highest screening uptake (100\%) and found relatively high HCV prevalence (8.6\%), but absolute numbers were small.

Four of the 22 programs screened primarily people from Asia, either through screening programs in Asia (Japan), or programs in Western countries targeting Asian migrants. In all but one of these programs, relatively high $\mathrm{HCV}$ prevalences were found, varying from $5.2 \%$ to $19.7 \%$. In contrast, the programs targeting those with occupational risk for $\mathrm{HCV}(\mathrm{n}=7)$ found relatively low $\mathrm{HCV}$ prevalences (all $<1.1 \%$, except for $3.6 \%$ among firefighters and $5.3 \%$ among health care workers involved with liver transplantations).

We did not notice clear differences in screening uptake or HCV prevalence related to the use of personal invitations for screening, the use of media to attract individuals for screening, and whether or not individuals were screened for other infections as well. In general, a lower 
HCV prevalence was found in the studies $(n=8)$ that provided anonymous screening for $\mathrm{HCV}$; however, most of these studies (6/8) targeted those with occupational risk for $\mathrm{HCV}$, explaining the lower prevalence.

Only one study compared the results of their outreach screening program with data collected in the same period at a screening clinic that is visited by individuals on their own initiative [54]. A higher prevalence of $\mathrm{HCV}$ was found during outreach screening (4.9\% versus $1.6 \%$, respectively). However, the number of individuals that returned to obtain their test results was much lower for the outreach approach (65.8\% versus $91.8 \%$, respectively). Only one study reported the proportion of identified HCV-infected individuals that started treatment (37\%) [53], but did not report how many of those reached a sustained virological response (SVR).

\section{Nonintegrated HCV screening programs in intermediate to high HCV-prevalence countries $(n=4)$ Program characteristics}

Table 1 presents the four nonintegrated HCV screening programs that were performed in intermediate to high HCV-prevalence countries (Taiwan [ $n=2]$, Pakistan [ $n=1$ ] and Egypt $[n=1])$. All studies targeted the general population; one targeted children less than 16 years of age. A study from Egypt reported household visits to personally invite individuals for screening [55]; the study among children reported personal invitations (method not specified) [56]. All except the study among children reported the use of media activities to attract individuals for screening. A risk-based screening selection was used in the program in Egypt, where screening was limited to those with symptoms and ALT levels $\geq 2$ times the upper limit of normal. None of the studies reported the possibility for individuals to participate anonymously. Two studies reported about the costs for participants to be screened; one of them offered screening free of cost, whereas the other program [57] offered screening at $20 \%$ of the market value. None of the studies used a comparison group for evaluation purposes. With respect to screening procedures, all four studies used venipuncture for specimen collection. A study from Pakistan [57] used a rapid HCV antibody test. In most (3/4) studies, participants were also screened for other infections (mostly HBV) but not for HIV.

\section{Program outcomes}

The number of individuals screened for $\mathrm{HCV}$ antibodies per program ranged from 47 to 157,720 . The screening uptake was reported in two studies; it was very low $(<1 \%)$ in a city screening program in Pakistan [57], and very high (93.6\%) in a screening program in kindergartens and schools in Taiwan [56]. Although the screening uptake in the latter was high, the prevalence was low (0.9\%). The HCV prevalences in the other programs varied from $4.4 \%$ in a community-based screening program in Taiwan [58] up to $78.8 \%$ in a program in Egypt that limited screening to those with symptoms and increased ALT levels [55]. None of the studies reported the proportion of $\mathrm{HCV}$-infected patients that started treatment and/or reached SVR.

\section{Integrated HCV screening programs}

We identified $41 \mathrm{HCV}$ screening programs in the following clinics that offer care not related to liver disease: sexually transmittable diseases (STD) clinics $(n=11)$; GP clinics $(n=10$, including two programs that also used a nonintegrated approach); Veterans Affairs (VA) clinics $(\mathrm{n}=5)$; antenatal/obstetric/fertility clinics $(\mathrm{n}=5)$; clinics for psychiatric patients $(\mathrm{n}=3)$; and other clinics or services $(n=7)$. Tables $2,3,4,5,6$ and 7 present the programs separately for each type of setting. All programs were carried out in low $\mathrm{HCV}$-prevalence countries.

\section{Clinics for sexually transmitted diseases $(n=11)$ Program characteristics}

The majority $(7 / 11)$ of the HCV screening programs in STD clinics were carried out in the USA (see Table 2). None of the studies reported the use of personal invitations or media to promote HCV screening. In five of the 11 programs, screening was limited to high-risk groups for $\mathrm{HCV}$, varying from single groups (e.g., people with a history of IDU [64], or MSM [60]) to individuals from multiple risk groups, such as those who have had body piercing or tattooing in unsanitary conditions, transfusion recipients before 1987 , or those who have had a needlestick injury [59]. None of the studies reported whether or not individuals were charged for screening, or whether anonymous participation in the screening program was possible. None of the programs used a comparison group for evaluation purposes. All programs used venipuncture for specimen collection.

\section{Program outcomes}

The number of individuals screened for HCV antibodies per program ranged from 618 to 90,424 . Six of the 11 programs reported the screening uptake, which varied from $14.0 \%$ to $95.8 \%$. The HCV prevalence varied from $0.1 \%$ to $28.0 \%$. Of the five studies that limited $\mathrm{HCV}$ screening to $\mathrm{HCV}$ risk groups, four reported a high prevalence $(>15 \%)$. In contrast, the prevalences in the six studies without a risk selection varied from $0.1 \%$ to $4.9 \%$. In all programs at the STD clinics, a history of IDU was found in the risk profile of the identified HCVinfected individuals, or was found associated with $\mathrm{HCV}$ infection. None of the studies reported the proportion of HCV-infected patients that started treatment and/or reached SVR. 
Table 1 Nonintegrated screening programs in intermediate to high HCV-prevalence countries (>2\%)

\begin{tabular}{|c|c|c|c|c|c|c|c|c|c|c|c|}
\hline \multicolumn{9}{|c|}{ Program characteristics } & \multicolumn{3}{|c|}{ Program outcomes } \\
\hline $\begin{array}{l}\text { First author, } \\
\text { year of } \\
\text { publication }\end{array}$ & $\begin{array}{l}\text { Calendar } \\
\text { year of data } \\
\text { collection }\end{array}$ & Population & $\begin{array}{l}\text { Country and } \\
\text { HCV prevalence } \\
\text { according to } \\
\text { CDC [23] }\end{array}$ & $\begin{array}{l}\text { Setting of } \\
\text { screening }\end{array}$ & $\begin{array}{l}\text { Duration of } \\
\text { screening } \\
\text { program }\end{array}$ & Other tests & $\begin{array}{l}\text { Pre-screening } \\
\text { selection }\end{array}$ & $\begin{array}{l}\text { Media } \\
\text { activities }\end{array}$ & $\begin{array}{l}\text { Screening uptake } \\
\text { and anti-HCV } \\
\text { prevalence } \\
(95 \% \mathrm{Cl})\end{array}$ & $\begin{array}{l}\text { Risk profile of } \\
\text { identified HCV } \\
\text { cases/Risk factors } \\
\text { associated with } \\
\text { HCV }\end{array}$ & $\begin{array}{l}\text { Follow-up of } \\
\text { HCV-infected } \\
\text { individuals }\end{array}$ \\
\hline \multirow{3}{*}{$\begin{array}{l}\text { Meky et al. } \\
2006 \text { [55] }\end{array}$} & \multirow[t]{3}{*}{$2002-2005$} & \multirow{3}{*}{$\begin{array}{l}\text { General } \\
\text { population }\end{array}$} & \multirow{3}{*}{$\begin{array}{l}\text { Egypt (6.6\%): } \\
\text { Two rural } \\
\text { villages in the } \\
\text { Nile Delta }\end{array}$} & \multirow{3}{*}{$\begin{array}{l}\text { Community } \\
\text { health clinic } \\
\text { and private } \\
\text { clinics for acute } \\
\text { cases }\end{array}$} & \multirow[t]{3}{*}{29 months } & \multirow{3}{*}{$\begin{array}{l}\text { HAV, HBV, } \\
\text { HEV, CMV, } \\
\text { Epstein-Barr }\end{array}$} & \multirow{3}{*}{$\begin{array}{l}\text { Only those with } \\
\text { symptoms and } \\
\text { ALT levels }=>2 \\
\text { times the upper } \\
\text { limit of normal } \\
\text { were tested }\end{array}$} & \multirow{3}{*}{ Yes } & Scr. uptake: NR & \multirow[t]{3}{*}{ NR } & \multirow[b]{2}{*}{$\begin{array}{l}\text { At } 2 \text { and } 6 \text { months } \\
\text { following initial } \\
\text { examination, follow- } \\
\text { up testing was done } \\
\text { to confirm or reclassify } \\
\text { the diagnosis (i.e., viral } \\
\text { clearance or persistent } \\
\text { infection). No data } \\
\text { was reported about } \\
\text { medical follow-up } \\
\text { of chronically } \\
\text { infected patients. }\end{array}$} \\
\hline & & & & & & & & & \multirow[t]{2}{*}{$\begin{array}{l}\text { Prevalence: } \\
\text { 78.7\% (37/47; } \\
\text { 95\% Cl:65.1-88.0* }\end{array}$} & & \\
\hline & & & & & & & & & & & $\begin{array}{l}\text { Outcomes: } \\
\text { RNA rate: } 70.2 \%(33 / 37) \\
\text { Start treatment: NR } \\
\text { SVR: NR }\end{array}$ \\
\hline \multirow{3}{*}{$\begin{array}{l}\text { Chen et al. } \\
2007 \text { [58] }\end{array}$} & \multirow[t]{3}{*}{ 1996-2005 } & \multirow{3}{*}{$\begin{array}{l}\text { General } \\
\text { population } \\
\text { aged } \geq 18 \text { yrs }\end{array}$} & \multirow{3}{*}{$\begin{array}{l}\text { Taiwan }\left(2.1 \%{ }^{\mathrm{a}}\right) \text { : } \\
\text { throughout the } \\
\text { country }\end{array}$} & \multirow{3}{*}{$\begin{array}{l}\text { Outreach } \\
\text { community } \\
\text { based } \\
\text { screening }\end{array}$} & \multirow[t]{3}{*}{10 years } & \multirow{3}{*}{$\begin{array}{l}\text { HBV, ALT, } \\
\text { AST }\end{array}$} & \multirow[t]{3}{*}{ No } & \multirow[t]{3}{*}{ Yes } & Scr. uptake: NR & \multirow[t]{3}{*}{ NR } & \multirow[b]{2}{*}{$\begin{array}{l}\text { Patients were } \\
\text { requested to return } \\
\text { to the collaborating } \\
\text { hospitals } \\
\text { for subsequent } \\
\text { management } \\
\text { (results were not } \\
\text { reported). }\end{array}$} \\
\hline & & & & & & & & & $\begin{array}{l}\text { Prevalence: } 4.4 \% \\
(6904 / 157720 \\
95 \% \text { Cl: } 4.3-4.5)^{* *}\end{array}$ & & \\
\hline & & & & & & & & & & & $\begin{array}{l}\text { Outcomes: } \\
\text { RNA rate: NR } \\
\text { Start treatment: NR } \\
\text { SVR: NR }\end{array}$ \\
\hline \multirow[t]{2}{*}{$\begin{array}{l}\text { Aslam \& Aslam } \\
2001 \text { [57] }\end{array}$} & \multirow[t]{2}{*}{2000} & \multirow[t]{2}{*}{$\begin{array}{l}\text { General } \\
\text { population }\end{array}$} & \multirow[t]{2}{*}{$\begin{array}{l}\text { Pakistan (6.6\%): } \\
\text { Lahore and } \\
\text { Gujranwala }\end{array}$} & \multirow[t]{2}{*}{$\begin{array}{l}\text { City screening } \\
\text { program }\end{array}$} & \multirow[t]{2}{*}{ NR } & \multirow[t]{2}{*}{ None } & \multirow[t]{2}{*}{ No } & \multirow[t]{2}{*}{ Yes } & $\begin{array}{l}\text { Scr. uptake: } \\
\text { Lahore: 0.01\% } \\
\text { 488/5063500 } \\
\text { Gujranwala: } 0.2 \% \\
\text { (1922/1124800) }\end{array}$ & \multirow{2}{*}{$\begin{array}{l}\text { Listed risk factors: } \\
\text { - Blood transfusion } \\
\text { - Surgery/dental } \\
\text { work } \\
\text { - Multiple factors } \\
\text { - Mostly other, } \\
\text { non-specified risk } \\
\text { factors }\end{array}$} & \multirow{2}{*}{$\begin{array}{l}\text { Patients were } \\
\text { informed } \\
\text { about the possibility } \\
\text { of eradication of the } \\
\text { virus, and treatment } \\
\text { in its early stages } \\
\text { (further data not } \\
\text { provided) } \\
\text { Outcomes: } \\
\text { RNA rate: NR } \\
\text { Start treatment: NR } \\
\text { SVR: NR }\end{array}$} \\
\hline & & & & & & & & & $\begin{array}{l}\text { Prevalence: Lahore: } \\
\text { 16\% (78/488; 95\% } \\
\text { Cl:13.0-19.5) } \\
\text { Gujranwala: 23.8\% } \\
(458 / 1922 ; 95 \% \\
\text { Cl: 22.0-25.8)* }\end{array}$ & & \\
\hline
\end{tabular}


Table 1 Nonintegrated screening programs in intermediate to high HCV-prevalence countries (>2\%) (Continued)

\begin{tabular}{|c|c|c|c|c|c|c|c|c|c|c|c|}
\hline \multirow[t]{2}{*}{$\begin{array}{l}\text { Lu et al. } \\
1998 \text { [56] }\end{array}$} & \multirow[t]{2}{*}{1994} & \multirow{2}{*}{$\begin{array}{l}\text { General } \\
\text { population } \\
<16 \text { yrs }\end{array}$} & \multirow{2}{*}{$\begin{array}{l}\text { Taiwan }\left(2.1 \%{ }^{\mathrm{a}}\right) \text { : } \\
\text { Paisha Township, } \\
\text { Penghu Islets }\end{array}$} & \multirow{2}{*}{$\begin{array}{l}\text { Kindergartens } \\
\text { and schools }\end{array}$} & \multirow[t]{2}{*}{1 month } & \multirow[t]{2}{*}{ HBV } & \multirow[t]{2}{*}{ No } & \multirow[t]{2}{*}{$N R$} & $\begin{array}{l}\text { Scr. uptake: 93.6\% } \\
\text { (1164/1243) }\end{array}$ & \multirow{2}{*}{$\begin{array}{l}\text { Listed risk factors: } \\
\text { - Surgery } \\
\text { - Intramuscular } \\
\text { injection } \\
\text { - Intravascul ar } \\
\text { injection, } \\
\text { - Intravascular } \\
\text { infusion }\end{array}$} & \multirow{2}{*}{$\begin{array}{l}\text { All anti-HCV positive } \\
\text { children were followed } \\
\text { annually for } 2 \text { years } \\
\text { with upper abdominal } \\
\text { sonography, AST, ALT, } \\
\text { anti-HCV and HCV RNA } \\
\text { No data was reported } \\
\text { about medical } \\
\text { follow-up of chronically } \\
\text { infected children. }\end{array}$} \\
\hline & & & & & & & & & $\begin{array}{l}\text { Prevalence: } 0.9 \% \\
\text { (11/1164; } 95 \% \\
\text { Cl: 0.5-1.7) overall* } \\
\text { 3-6 yrs: 0\% } \\
7-12 \text { yrs: } 0.8 \% \\
13-15 \text { yrs: } 1.9 \%\end{array}$ & & \\
\hline
\end{tabular}

Outcomes:

RNA rate: $27.3 \%(3 / 11)$

Start treatment: NR

SVR: NR

Note: $\mathrm{Cl}=$ confidence interval; $\mathrm{NR}=$ not reported; IDU = injecting drug use; $\mathrm{HCV}=$ hepatitis $\mathrm{C}$ virus; $\mathrm{HBV}=$ hepatitis $\mathrm{B}$ virus; $\mathrm{HAV}=$ hepatitis $\mathrm{A}$ virus; $\mathrm{HEV}=$ hepatitis $\mathrm{E}$ virus; $\mathrm{CMV}=$ cytomegalovirus; $\mathrm{ALT}=$ alanine

aminotransferase; AST = aspartate aminotransferase; SVR = sustained virological response.

*HCV-antibody prevalence is considered suboptimal (data were collected before 1994 when sensitivity/specificity of tests was not optimal, or reactive HCV-antibody test results were not confirmed by immunoblot).

**The reliability of the reported HCV-antibody prevalence is undecided (data were collected after 1993, but the diagnostic tests are unspecified, or other than described below (see ***), or dried blood spots or oral fluid samples were used).

***HCV-antibody prevalence is considered valid; data were collected after 1993, and reactive HCV-antibody test results were confirmed by second or higher generation immunoblot assays from Ortho, Chiron, Novartis (RIBA), Innogenetics (LiaTek), Pasteur (DECISCAN HCV), Genelabs Diagnostics (HCV BLOT), or Mikrogen (recomBlot HCV IgG 2.0).

${ }^{\mathrm{a}} \mathrm{HCV}$ prevalence based on prevalence of country neighbours. 
Table 2 Integrated screening programs at clinics for sexually transmitted diseases (STD)

\begin{tabular}{|c|c|c|c|c|c|c|c|c|c|c|c|}
\hline \multicolumn{9}{|c|}{ Program characteristics } & \multicolumn{3}{|c|}{ Program outcomes } \\
\hline $\begin{array}{l}\text { First author, } \\
\text { year of } \\
\text { publication }\end{array}$ & $\begin{array}{l}\text { Calendar } \\
\text { year of data } \\
\text { collection }\end{array}$ & Population & $\begin{array}{l}\text { Country and } \\
\text { HCV prevalence } \\
\text { according to } \\
\text { CDC [23] }\end{array}$ & $\begin{array}{l}\text { Setting of } \\
\text { screening }\end{array}$ & $\begin{array}{l}\text { Duration of } \\
\text { screening } \\
\text { program }\end{array}$ & $\begin{array}{l}\text { Other } \\
\text { tests }\end{array}$ & $\begin{array}{l}\text { Prescreening } \\
\text { selection }\end{array}$ & $\begin{array}{l}\text { Media } \\
\text { activities }\end{array}$ & $\begin{array}{l}\text { Screening } \\
\text { uptake and } \\
\text { anti-HCV } \\
\text { prevalence } \\
(95 \% \mathrm{Cl})\end{array}$ & $\begin{array}{l}\text { Risk profile of } \\
\text { identified HCV } \\
\text { cases/Risk } \\
\text { factors } \\
\text { associated with } \\
\text { HCV }\end{array}$ & $\begin{array}{l}\text { Follow-up of } \\
\text { HCV-infected } \\
\text { individuals }\end{array}$ \\
\hline \multirow[t]{2}{*}{$\begin{array}{l}\text { D'Souza et al. } \\
2003 \text { [59] }\end{array}$} & \multirow[t]{2}{*}{2001} & \multirow[t]{2}{*}{$\begin{array}{l}\text { STD clinic } \\
\text { clients }\end{array}$} & \multirow[t]{2}{*}{$\begin{array}{l}\text { USA (1.9\%): } \\
\text { Houston }\end{array}$} & \multirow[t]{2}{*}{ STD clinic } & \multirow[t]{2}{*}{9 months } & \multirow[t]{2}{*}{ STD } & \multirow{2}{*}{$\begin{array}{l}\text { Yes, risk } \\
\text { assessment } \\
\text { questionnaire. } \\
\text { screening } \\
\text { offered to } \\
\text { high-risk } \\
\text { groups }^{\text {a }}\end{array}$} & \multirow[t]{2}{*}{ NR } & $\begin{array}{l}\text { Scr. uptake: } \\
95.8 \% \\
(822 / 859)\end{array}$ & \multirow{2}{*}{$\begin{array}{l}\text { Multivariable regr. } \\
\text { analysis: } \\
\text { - History of IDU } \\
\text { - Age } \geq 25 \text { yrs } \\
\text { - Heroin use } \\
\text { - Non-transfusion/ } \\
\text { transplantation } \\
\text { blood exposure } \\
\text { - Shared straw to } \\
\text { snort drugs }\end{array}$} & \multirow{2}{*}{$\begin{array}{l}\text { Patients were referred } \\
\text { to appropriate } \\
\text { settings for } \\
\text { follow-up (no results } \\
\text { were reported). } \\
\text { Outcomes: } \\
\text { RNA rate: NR } \\
\text { Start treatment: NR } \\
\text { SVR: NR }\end{array}$} \\
\hline & & & & & & & & & $\begin{array}{l}\text { Prevalence: } \\
\text { 15.3\% (126/ } \\
822 ; 95 \% \\
\text { Cl:12.7-17.7)* }\end{array}$ & & \\
\hline \multirow[t]{2}{*}{$\begin{array}{l}\text { Scott et al. } \\
2010 \text { [60] }\end{array}$} & \multirow[t]{2}{*}{2007} & \multirow[t]{2}{*}{$\begin{array}{l}\text { STD clinic } \\
\text { clients }\end{array}$} & \multirow{2}{*}{$\begin{array}{l}\text { UK (1.1\%): } \\
\text { London, } \\
\text { Chelsea and } \\
\text { Westminister } \\
\text { hospital }\end{array}$} & \multirow[t]{2}{*}{$\begin{array}{l}\text { STD clinic } \\
\text { in hospital }\end{array}$} & \multirow[t]{2}{*}{6 months } & \multirow[t]{2}{*}{ STD } & \multirow[t]{2}{*}{ Yes, MSM } & \multirow[t]{2}{*}{$N R$} & $\begin{array}{l}\text { Scr. uptake: } \\
68.6 \% \\
(2309 / 3365)\end{array}$ & \multirow{2}{*}{$\begin{array}{l}\text { Listed risk factors: } \\
\text { - HIV+ } \\
\text { - History of IDU } \\
\text { - Unprotected anal } \\
\text { intercourse }\end{array}$} & $\begin{array}{l}\text { HCV RNA was tested } \\
\text { in } 13 / 15 \mathrm{HCV} \text { antibody } \\
\text { positive persons. }\end{array}$ \\
\hline & & & & & & & & & $\begin{array}{l}\text { Prevalence: } \\
\text { 0.6\% (15/2309; } \\
\text { 95\% Cl:0.4- } \\
\text { 1.1\%)** }\end{array}$ & & $\begin{array}{l}\text { Outcomes: } \\
\text { RNA rate: } 69.2 \%(9 / 13) \\
\text { Start treatment: NR } \\
\text { SVR: NR }\end{array}$ \\
\hline \multirow[t]{2}{*}{$\begin{array}{l}\text { Weisbord et al. } \\
2003 \text { [61] }\end{array}$} & \multirow[t]{2}{*}{2001} & \multirow[t]{2}{*}{$\begin{array}{l}\text { STD clinic } \\
\text { clients }\end{array}$} & \multirow[t]{2}{*}{$\begin{array}{l}\text { USA (1.9\%): } \\
\text { Miami }\end{array}$} & \multirow[t]{2}{*}{ STD clinic } & \multirow[t]{2}{*}{3 months } & \multirow[t]{2}{*}{$\begin{array}{l}\text { HAV, } \\
\text { HBV }\end{array}$} & \multirow[t]{2}{*}{ No } & \multirow[t]{2}{*}{$N R$} & $\begin{array}{l}\text { Scr. uptake: } \\
50.3 \% \\
(687 / 1365)\end{array}$ & \multirow{2}{*}{$\begin{array}{l}\text { Multivariable regr. } \\
\text { analysis: } \\
\text { - History of IDU } \\
\text { - Sex with HCV + } \\
\text { person } \\
\text { - Spent } \geq 1 \text { day } \\
\text { in prison } \\
\text { - Older age }\end{array}$} & \multirow{2}{*}{$\begin{array}{l}\text { Patients received their } \\
\text { test results within two } \\
\text { weeks (no further } \\
\text { results reported). } \\
\text { Outcomes: } \\
\text { RNA rate: NR } \\
\text { Start treatment: NR } \\
\text { SVR: NR }\end{array}$} \\
\hline & & & & & & & & & $\begin{array}{l}\text { Prevalence: } \\
4.7 \% \text { (32/687; } \\
95 \% \text { Cl: } 3.3- \\
6.5)^{* * *}\end{array}$ & & \\
\hline \multirow[t]{3}{*}{$\begin{array}{l}\text { Gunn et al. } \\
2003 \text { [62] }\end{array}$} & \multirow[t]{3}{*}{ 1999-2000 } & \multirow[t]{3}{*}{$\begin{array}{l}\text { STD clinic } \\
\text { clients }\end{array}$} & $\begin{array}{l}\text { USA (1.9\%): } \\
\text { San Diego }\end{array}$ & STD clinic & 8 months & STD & No & No & $\begin{array}{l}\text { Scr. uptake: } \\
\text { NR }\end{array}$ & $\begin{array}{l}\text { Multivariable regr. } \\
\text { analysis: }\end{array}$ & $\begin{array}{l}\text { Post-test counseling } \\
\text { was offered. A list of }\end{array}$ \\
\hline & & & & & & & & & $\begin{array}{l}\text { Prevalence: } \\
4.9 \%(165 / \\
3367 ; 95 \% \\
\text { Cl: } 4.2-5.7)^{* * *}\end{array}$ & $\begin{array}{l}\text { - Age } \geq 30 \text { yrs } \\
\text { - Ever in jail } \\
\text { - Blood transfusion } \\
\text { before } 1992 \\
\text { - History of } \\
\text { bacterial STD } \\
\text { - IDU sex partner }\end{array}$ & $\begin{array}{l}\text { medical care } \\
\text { resources was } \\
\text { provided. } \\
\text { In total, 136/165 were } \\
\text { interviewed of whom } \\
44 \% \text { had no medical } \\
\text { insurance, but } 87 \% \\
\text { planned to have a } \\
\text { medical evaluation. }\end{array}$ \\
\hline & & & & & & & & & & & $\begin{array}{l}\text { Outcomes: } \\
\text { RNA rate: NR } \\
\text { Start treatment: NR } \\
\text { SVR: NR }\end{array}$ \\
\hline
\end{tabular}


Table 2 Integrated screening programs at clinics for sexually transmitted diseases (STD) (Continued)

\begin{tabular}{|c|c|c|c|c|c|c|c|c|c|c|c|}
\hline $\begin{array}{l}\text { Mapagu et al. } \\
2008 \text { [63] }\end{array}$ & $2000-2002$ & $\begin{array}{l}\text { STD clinic } \\
\text { clients }\end{array}$ & $\begin{array}{l}\text { Australia (2\%): } \\
\text { Canberra }\end{array}$ & STD clinic & 3 years & $\begin{array}{l}\text { STD, } \\
\text { BBV }\end{array}$ & No & NR & $\begin{array}{l}\text { Scr. uptake: } \\
46.0 \% \\
(3113 / 6774) \\
\text { Prevalence: } \\
\text { 3.1\% (95/3113; } \\
95 \% \text { Cl: } 2.5- \\
3.7 \%)^{* *}\end{array}$ & $\begin{array}{l}\text { Listed risk factors: } \\
\text { - History of IDU } \\
\text { - Tatoos } \\
\text { - Body piercings } \\
\text { - Blood transfusion } \\
\text { - IDU partner } \\
\text { - Needle stick } \\
\text { - Mother HCV+ } \\
\text { - Medical treatment } \\
\text { overseas in } \\
\text { childhood } \\
\text { - Prison }\end{array}$ & $\begin{array}{l}\text { Of the } 95 \mathrm{HCV} \\
\text { antibody positive } \\
\text { persons, } 47 \text { were } \\
\text { tested for HCV RNA. } \\
\text { Outcomes: } \\
\text { RNA rate: } 61.7 \% \\
\text { (29/47) } \\
\text { Start treatment: NR } \\
\text { SVR: NR }\end{array}$ \\
\hline $\begin{array}{l}\text { Zimmerman } \\
\text { et al. } 2007 \text { [64] }\end{array}$ & $2001-2005$ & $\begin{array}{l}\text { STD clinic } \\
\text { clients }\end{array}$ & $\begin{array}{l}\text { USA (1.9\%): } \\
\text { Illinois } \\
\text { excluding } \\
\text { Chicago }\end{array}$ & STD clinics & 5 years & $\begin{array}{l}\text { HBV } \\
\text { (only } \\
\text { 2001), } \\
\text { STD }\end{array}$ & $\begin{array}{l}\text { Yes: 2001: } \\
\text { IDU and } \\
\text { snorting } \\
\text { drugs were } \\
\text { criteria. From } \\
\text { 2002: only IDU }\end{array}$ & NR & $\begin{array}{l}\text { Scr. uptake: } \\
\text { NR } \\
\text { Prevalence: } \\
\text { 21.2\% (646/ } \\
3042 ; 95 \% \\
\text { Cl: } 19.8-22.7)^{* * *}\end{array}$ & $\begin{array}{l}\text { Listed risk factors: } \\
\text { - Mainly IDU }\end{array}$ & $\begin{array}{l}\text { Because of inadequate } \\
\text { resources, the referrals } \\
\text { and follow-up were } \\
\text { not monitored. } \\
\text { Outcomes: } \\
\text { RNA rate: NR } \\
\text { Start treatment: NR } \\
\text { SVR: NR }\end{array}$ \\
\hline $\begin{array}{l}\text { Subiadur et al. } \\
2007 \text { [65] }\end{array}$ & $2000-2005$ & $\begin{array}{l}\text { STD clinic } \\
\text { clients }\end{array}$ & $\begin{array}{l}\text { USA (1.9\%): } \\
\text { Denver }\end{array}$ & STD clinics & 6 years & $\begin{array}{l}\text { STD, } \\
\text { HIV }\end{array}$ & $\begin{array}{l}\text { Yes: IDU, } \\
\text { HCV-infected } \\
\text { sex partner, } \\
\text { blood } \\
\text { transfusion } \\
\text { before } 1992\end{array}$ & NR & $\begin{array}{l}\text { Scr. uptake: NR } \\
\text { Prevalence: } \\
\text { 28.0\%. (467/ } \\
\text { 1666; 95\% } \\
\text { Cl: } 25.9-30.2)^{* *}\end{array}$ & NR & $\begin{array}{l}\text { Patients were referred } \\
\text { to a specialist but a } \\
\text { sub-study of } 65 / 467 \\
\text { clients showed that } \\
<20 \% \text { followed } \\
\text { through with } \\
\text { recommended } \\
\text { services. } \\
\text { Outcomes: } \\
\text { RNA rate: NR } \\
\text { Start treatment: NR } \\
\text { SVR: NR }\end{array}$ \\
\hline $\begin{array}{l}\text { Heseltine \& } \\
\text { McFarlane } \\
2007 \text { [66] }\end{array}$ & $2000-2005$ & $\begin{array}{l}\text { Not specified; } \\
\text { clients of } \\
\text { the various } \\
\text { settings }\end{array}$ & $\begin{array}{l}\text { USA (1.9\%): } \\
\text { Texas }\end{array}$ & $\begin{array}{l}\text { Several HIV/STD } \\
\text { service providers: } \\
\text { HIV counseling } \\
\text { and testing sites; } \\
\text { drug treatment } \\
\text { facilities, corrections } \\
\text { facilities, field visit/ } \\
\text { outreach sites } \\
\text { (e.g., bars, adult } \\
\text { bookstores, } \\
\text { homeless } \\
\text { shelters), } \\
\text { STD clinics, family } \\
\text { planning clinic, } \\
\text { primary health } \\
\text { care facility }\end{array}$ & 6 years & $\begin{array}{l}\text { STD, } \\
\text { HIV }\end{array}$ & $\begin{array}{l}\text { Yes: IDU, sharing } \\
\text { equipment used } \\
\text { to snort drugs; } \\
\text { having received a } \\
\text { tattoo or piercing } \\
\text { under unsanitary } \\
\text { conditions; having } \\
50 \text { or more lifetime } \\
\text { sex partners; } \\
\text { exchanging sex } \\
\text { for money; having } \\
\text { sex with an HCV- } \\
\text { positive person; } \\
\text { people with some } \\
\text { medical exposures } \\
\text { and occupations }\end{array}$ & No & $\begin{array}{l}\text { Scr. uptake: } \\
\text { NR } \\
\text { Prevalence: } \\
\text { 23.2\% (8964/ } \\
\text { 38717; 95\% } \\
\text { Cl: 22.7-23.6)*** }\end{array}$ & $\begin{array}{l}\text { Listed risk factors: } \\
\text { - History of IDU } \\
\text { (main risk factor) } \\
\text { - Risky tattoo/ } \\
\text { piercing } \\
\text { - Risky sex } \\
\text { - Blood or medical } \\
\text { exposure } \\
\text { - Sharing snorting } \\
\text { equipment } \\
\text { - Occupational } \\
\text { exposure }\end{array}$ & $\begin{array}{l}\text { Post-test counseling } \\
\text { and referral to public } \\
\text { and private providers } \\
\text { in the local community } \\
\text { was offered. } 50.3 \% \text { of } \\
776 \text { substance abuse } \\
\text { referrals, } 22.4 \% \text { of } 4410 \\
\text { medical evaluation } \\
\text { referrals, and } 17.4 \% \text { of } \\
2299 \text { vaccination } \\
\text { referrals were } \\
\text { confirmed. } \\
\text { Outcomes: } \\
\text { RNA rate: NR } \\
\text { Start treatment: NR } \\
\text { SVR: NR }\end{array}$ \\
\hline
\end{tabular}


Table 2 Integrated screening programs at clinics for sexually transmitted diseases (STD) (Continued)

\begin{tabular}{|c|c|c|c|c|c|c|c|c|c|c|c|}
\hline \multirow[t]{3}{*}{$\begin{array}{l}\text { Gunn et al. } \\
2001 \text { [67] }\end{array}$} & \multirow[t]{3}{*}{1998} & \multirow[t]{3}{*}{$\begin{array}{l}\text { STD clinic } \\
\text { clients }\end{array}$} & \multirow[t]{3}{*}{$\begin{array}{l}\text { USA (1.9\%): } \\
\text { San Diego }\end{array}$} & \multirow[t]{3}{*}{ STD clinic } & \multirow[t]{3}{*}{6 weeks } & \multirow[t]{3}{*}{ HBV } & \multirow[t]{3}{*}{ No } & \multirow[t]{3}{*}{ No } & $\begin{array}{l}\text { Scr. uptake: } \\
82.4 \% \text { (618/ } \\
750)\end{array}$ & \multirow{3}{*}{$\begin{array}{l}\text { Listed risk factors: } \\
\text { - History of IDU } \\
\text { - Among non-IDU: } \\
\text { age } \geq 30 \text { yrs }\end{array}$} & \multirow{2}{*}{$\begin{array}{l}\text { HCV-positive persons } \\
\text { were given information } \\
\text { about the prevention } \\
\text { of HCV transmission } \\
\text { and a list of facilities } \\
\text { where they might } \\
\text { obtain a medical } \\
\text { evaluation. Appr. } 8 \\
\text { months after the } \\
\text { project, } 14 / 21 \text { clients } \\
\text { were contacted of } \\
\text { whom } 6 \text { had seen a } \\
\text { physician for medical } \\
\text { evaluation. }\end{array}$} \\
\hline & & & & & & & & & \multirow[t]{2}{*}{$\begin{array}{l}\text { Prevalence: } \\
3.4 \%(21 / 618 ; \\
95 \% \text { Cl: } 2.2- \\
5.1)^{* *}\end{array}$} & & \\
\hline & & & & & & & & & & & $\begin{array}{l}\text { Outcomes: } \\
\text { RNA rate: NR } \\
\text { Start treatment: NR } \\
\text { SVR: NR }\end{array}$ \\
\hline $\begin{array}{l}\text { Ellks } 2010 \\
\text { [68] }\end{array}$ & 2008 & $\begin{array}{l}\text { Visitors of } \\
\text { sexual and }\end{array}$ & $\begin{array}{l}\text { UK (1.1\%): } \\
\text { Crewe }\end{array}$ & $\begin{array}{l}\text { STD and } \\
\text { reproductive }\end{array}$ & 1 year & $\begin{array}{l}\text { HIV, } \\
\text { syphilis, }\end{array}$ & No & No & $\begin{array}{l}\text { Scr. uptake: } \\
\text { NR }\end{array}$ & $\begin{array}{l}\text { Listed risk factors: } \\
\text { - History of IDU }\end{array}$ & $\begin{array}{l}\text { There were follow-up } \\
\text { appointments for those }\end{array}$ \\
\hline & & health service & & $\begin{array}{l}\text { (integrated } \\
\text { service) }\end{array}$ & & & & & $\begin{array}{l}\text { Prevalence: } \\
0.1 \% \text { (8/5468; } \\
95 \% \text { Cl: } 0.1- \\
0.3)^{* *}\end{array}$ & snorted drugs & $\begin{array}{l}\text { Outcomes: } \\
\text { RNA rate: NR } \\
\text { Start treatment: NR } \\
\text { SVR: NR }\end{array}$ \\
\hline \multirow[t]{4}{*}{$\begin{array}{l}\text { Tweed et al. } \\
2010 \text { [69] }\end{array}$} & \multirow[t]{4}{*}{$2002-2007$} & \multirow{4}{*}{$\begin{array}{l}\text { Visitors of } \\
\text { STD and } \\
\text { contraception } \\
\text { and sexual } \\
\text { health clinics, } \\
\text { and specialist } \\
\text { HIV services }\end{array}$} & \multirow[t]{4}{*}{$\begin{array}{l}\text { UK (1.1\%): } \\
\text { Throughout } \\
\text { the country }\end{array}$} & \multirow{4}{*}{$\begin{array}{l}\text { STD clinics, } \\
\text { contraception } \\
\text { and sexual health } \\
\text { clinics, specialist } \\
\text { HIV services }\end{array}$} & \multirow[t]{4}{*}{6 years } & \multirow[t]{4}{*}{$\begin{array}{l}\text { Likely } \\
\text { STD/HIV }\end{array}$} & \multirow[t]{4}{*}{ No } & \multirow[t]{4}{*}{ NR } & \multirow{4}{*}{$\begin{array}{l}\text { Scr. uptake: } \\
\text { estimated } \\
\text { at } 14.0 \% \\
\text { Prevalence: } \\
3.2 \%(2858 / \\
90424 ; 95 \% \\
\text { Cl: } 3.04-3.27)^{* *}\end{array}$} & \multirow{4}{*}{$\begin{array}{l}\text { Multivariable } \\
\text { regr. analysis: } \\
\text { - Male sex } \\
\text { - Age } 35+ \\
\text { - History of IDU }\end{array}$} & \multirow{2}{*}{$\begin{array}{l}\text { Those who tested } \\
\text { positive were } \\
\text { followed-up with } \\
\text { clinicians (no data } \\
\text { reported). }\end{array}$} \\
\hline & & & & & & & & & & & \\
\hline & & & & & & & & & & & $\begin{array}{l}\text { Of the antiHCV positive } \\
\text { individuals, } 60.1 \% \\
\text { (1719/2858) were } \\
\text { tested for HCV RNA. }\end{array}$ \\
\hline & & & & & & & & & & & $\begin{array}{l}\text { Outcomes: } \\
\text { RNA rate: } \\
\text { 69.2\% (1191/1719) } \\
\text { Start treatment: NR } \\
\text { SVR: NR }\end{array}$ \\
\hline
\end{tabular}

Note: $\mathrm{Cl}=$ confidence interval; $\mathrm{NR}=$ not reported; $\mathrm{STD}=$ sexually transmitted disease; $\mathrm{BBV}=$ blood-borne virus; IDU = injecting drug use; $\mathrm{HCV}=$ hepatitis $\mathrm{C}$ virus; $\mathrm{HBV}=$ hepatitis $\mathrm{B}$ virus; $\mathrm{HAV}=$ hepatitis $\mathrm{A}$ virus; HIV = human immunodeficiency virus; MSM = men who have sex with men; SVR= sustained virological response.

*HCV-antibody prevalence is considered suboptimal (data were collected before 1994 when sensitivity/specificity of tests was not optimal, or reactive HCV-antibody test results were not confirmed by immunoblot).

**The reliability of the reported HCV-antibody prevalence is undecided (data were collected after 1993, but the diagnostic tests are unspecified, or other than described below, or dried blood spots or oral fluid samples were used).

***HCV-antibody prevalence is considered valid; data were collected after 1993, and reactive HCV-antibody test results were confirmed by second or higher generation immunoblot assays from Ortho, Chiron, Novartis (RIBA), Innogenetics (LiaTek), Pasteur (DECISCAN HCV), Genelabs Diagnostics (HCV BLOT), or Mikrogen (recomBlot HCV IgG 2.0).

a History of IDU, body piercing/tattooing in unsanitary conditions, transfusion recipients before 1987, needlestick injury, hemodialysis patients, those born to mothers with documented HCV infection, individuals who

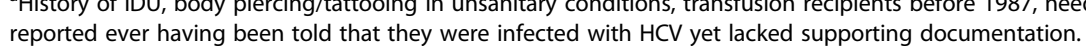


Table 3 Integrated screening programs at general practitioner (GP) clinics

\begin{tabular}{|c|c|c|c|c|c|c|c|c|c|c|c|}
\hline \multicolumn{9}{|c|}{ Program characteristics } & \multicolumn{3}{|c|}{ Program outcomes } \\
\hline $\begin{array}{l}\text { First author, } \\
\text { year of } \\
\text { publication }\end{array}$ & $\begin{array}{l}\text { Calendar } \\
\text { year of data } \\
\text { collection }\end{array}$ & Population & $\begin{array}{l}\text { Country } \\
\text { and HCV } \\
\text { prevalence } \\
\text { according } \\
\text { to CDC [23] }\end{array}$ & $\begin{array}{l}\text { Setting of } \\
\text { screening }\end{array}$ & $\begin{array}{l}\text { Duration of } \\
\text { screening } \\
\text { program }\end{array}$ & $\begin{array}{l}\text { Other } \\
\text { tests }\end{array}$ & $\begin{array}{l}\text { Pre-screening } \\
\text { selection }\end{array}$ & $\begin{array}{l}\text { Media } \\
\text { activities }\end{array}$ & $\begin{array}{l}\text { Screening } \\
\text { uptake and } \\
\text { anti-HCV } \\
\text { prevalence } \\
(95 \% \mathrm{Cl})\end{array}$ & $\begin{array}{l}\text { Risk profile } \\
\text { of identified HCV } \\
\text { cases/Risk factors } \\
\text { associated with HCV }\end{array}$ & $\begin{array}{l}\text { Follow-up of } \\
\text { HCV-infected } \\
\text { individuals }\end{array}$ \\
\hline \multirow[t]{2}{*}{$\begin{array}{l}\text { Monnet et al. } \\
\text { 2000, } 2009 \\
\text { [70] }\end{array}$} & \multirow[t]{2}{*}{ 1997-1998 } & \multirow[t]{2}{*}{$\begin{array}{l}\text { Patient of GP } \\
\text { clinics, health } \\
\text { centres, } \\
\text { occupational } \\
\text { physicians, } \\
\text { prison health } \\
\text { service, public } \\
\text { laboratories }\end{array}$} & \multirow[t]{2}{*}{$\begin{array}{l}\text { France (1.1\%): } \\
\text { Le Doubs }\end{array}$} & \multirow[t]{2}{*}{$\begin{array}{l}\text { GP clinics, } \\
\text { health centre, } \\
\text { occupational } \\
\text { physicians, } \\
\text { prison health } \\
\text { service, public } \\
\text { laboratories }\end{array}$} & \multirow[t]{2}{*}{1 year } & \multirow[t]{2}{*}{ None } & \multirow[t]{2}{*}{$\begin{array}{l}\text { Yes, no } \\
\text { previous } \\
\text { positive HCV } \\
\text { serology, and } \\
\text { at least having } \\
\text { one risk factor: } \\
\text { transfusion } \\
\text { before 1991, } \\
\text { (ex-IDU, (ex-) } \\
\text { snorting } \\
\text { cocaine, } \\
\text { tattoo, HCV } \\
\text { diagnosis in } \\
\text { living } \\
\text { environment }\end{array}$} & \multirow[t]{2}{*}{ Yes } & $\begin{array}{l}\text { Scr. uptake: } \\
82.5 \% \text { (782/948) } \\
\\
\text { Prevalence: 4.0\% } \\
(31 / 782 ; 95 \% \mathrm{Cl} \text {. } \\
2.8-5.6)^{*}\end{array}$ & \multirow[t]{2}{*}{$\begin{array}{l}\text { Multivariable regr. } \\
\text { analysis: } \\
\text { - Age } 30+ \\
\text { - Drug use }\end{array}$} & $\begin{array}{l}70.9 \%(22 / 31) \\
\text { attended the } \\
\text { hepatologist } \\
\text { for HCV RNA testing. } \\
\text { Of those who } \\
\text { tested HCV RNA } \\
\text { positive, } 10 \text { had } \\
\text { elevated ALAT of } \\
\text { which } 8 \text { had a } \\
\text { biopsy. Based on } \\
\text { the results, } 5 \text { were } \\
\text { indicated for } \\
\text { treatment (no results } \\
\text { reported). }\end{array}$ \\
\hline & & & & & & & & & & & $\begin{array}{l}\text { Outcomes: } \\
\text { RNA rate: } 86.4 \% \\
\text { (19/22) } \\
\text { Start treatment: NR } \\
\text { SVR: NR }\end{array}$ \\
\hline \multirow[t]{4}{*}{$\begin{array}{l}\text { Anderson } \\
\text { et al. } 2009 \\
\text { [71] }\end{array}$} & \multirow[t]{4}{*}{ 2003-2004 } & \multirow[t]{4}{*}{$\begin{array}{l}\text { GP patients } \\
\text { aged } 30-54 \text { yrs }\end{array}$} & \multirow[t]{4}{*}{$\begin{array}{l}\text { Scotland } \\
\text { (1.1\%): socio- } \\
\text { economically } \\
\text { deprived area } \\
\text { of Glasgow }\end{array}$} & \multirow[t]{4}{*}{$\begin{array}{l}\text { GP clinics } \\
\text { (intervention } \\
\text { clinic and } \\
\text { comparison } \\
\text { clinic) }\end{array}$} & \multirow[t]{4}{*}{6 months } & \multirow[t]{4}{*}{ None } & \multirow{3}{*}{$\begin{array}{l}\text { No; in } \\
\text { intervention } \\
\text { practice all } \\
\text { individuals } \\
\text { aged } 30- \\
54 \text { yrs who } \\
\text { attended non- } \\
\text { urgent ap- } \\
\text { pointments } \\
\text { were offered } \\
\text { HCV screening. }\end{array}$} & \multirow{4}{*}{$\begin{array}{l}\text { Eligible } \\
\text { patients in } \\
\text { intervention } \\
\text { practice } \\
\text { received } \\
\text { information } \\
\text { leaflet }\end{array}$} & $\begin{array}{l}\text { Scr. uptake: } \\
\text { Intervention } \\
\text { clinic: } 27.8 \% \\
(117 / 421)\end{array}$ & \multirow[t]{4}{*}{$\begin{array}{l}\text { Multivariable regr. } \\
\text { analysis } \\
\text { - History of IDU }\end{array}$} & \multirow{4}{*}{$\begin{array}{l}\text { HCV RNA positive } \\
\text { patients ( } \mathrm{n}=11 \text { ) } \\
\text { were referred to a } \\
\text { specialist and } \\
\text { all attended } \geq 1 \\
\text { appointment. } \\
\text { Four years later, } \\
8 \text { were lost to } \\
\text { follow-up, } 2 \text { started } \\
\text { treatment, and 1 } \\
\text { achieved an SVR. } \\
\text { Outcomes: } \\
\text { RNA rate: } 73.3 \% \\
\text { (11/15) } \\
\text { Start treatment: } \\
\text { 18.2\% }(2 / 11) \\
\text { SVR: } 50.0 \%(1 / 2)\end{array}$} \\
\hline & & & & & & & & & $\begin{array}{l}\text { Comparison } \\
\text { clinic: not } \\
\text { applicable }\end{array}$ & & \\
\hline & & & & & & & & & $\begin{array}{l}\text { Prevalence: } \\
\text { Intervention } \\
\text { clinic: } 12.8 \% \text { (15/ }\end{array}$ & & \\
\hline & & & & & & & $\begin{array}{l}\text { In comparison } \\
\text { practice, no } \\
\text { intervention was } \\
\text { carried out. }\end{array}$ & & $\begin{array}{l}\text { 117; } 95 \% \mathrm{Cl} \text { : } \\
\text { 7.9-20.0) } \\
\text { Comparison } \\
\text { clinic: No } \\
\text { individuals were } \\
\text { tested during } \\
\text { study period.** }\end{array}$ & & \\
\hline $\begin{array}{l}\text { Pauti et al. } \\
2008 \text { [44] }\end{array}$ & 2007 & $\begin{array}{l}\text { People with } \\
\text { poor access to } \\
\text { health care, } \\
\text { mostly migrants }\end{array}$ & $\begin{array}{l}\text { France (1.1\%): } \\
\text { Saint-Denis } \\
\text { and Paris } \\
\text { areas }\end{array}$ & $\begin{array}{l}\text { Health care } \\
\text { and advice } \\
\text { centers of } \\
\text { Médecins du } \\
\text { Monde }^{b}\end{array}$ & $\begin{array}{l}4 \text { years, but } \\
\text { data from } 1 \\
\text { year are } \\
\text { reported }\end{array}$ & $\begin{array}{l}\text { HIV, } \\
\text { HBV }\end{array}$ & No & No & $\begin{array}{l}\text { Scr. uptake: NR } \\
\text { Prevalence: } 5.9 \% \\
\text { (70/1196; 95\% } \\
\text { Cl: 4.7-7.3)** }\end{array}$ & $\begin{array}{l}\text { Listed risk factors: } \\
\text { - North and Middle } \\
\text { Africa } \\
\text { - Sub-Saharan Africa } \\
\text { - Eastern Europe }\end{array}$ & $\begin{array}{l}\text { The objective of } \\
\text { the project was to } \\
\text { offer full access to } \\
\text { treatment, but } \\
\text { actual results are } \\
\text { not reported }\end{array}$ \\
\hline
\end{tabular}




\begin{tabular}{|c|c|c|c|c|c|c|c|c|c|c|c|}
\hline \multirow{2}{*}{$\begin{array}{l}\text { Uddin et al. } \\
2010 \text { [46] }^{a}\end{array}$} & \multirow[t]{2}{*}{$N R$} & \multirow[t]{2}{*}{ GP patients } & \multirow{2}{*}{$\begin{array}{l}\text { UK (1.1\%): } \\
\text { East London, } \\
\text { West London, } \\
\text { Walsall, } \\
\text { Sandwell, } \\
\text { Bradford }\end{array}$} & \multirow{2}{*}{$\begin{array}{l}\text { GP clinic (and } \\
\text { at community } \\
\text { centers, see } \\
\text { Additional file } \\
\text { 1: Table S1) }\end{array}$} & \multirow[t]{2}{*}{ NR } & \multirow[t]{2}{*}{ HBV } & \multirow{2}{*}{$\begin{array}{l}\text { Yes, } \\
\text { immigrants } \\
\text { from the Indian } \\
\text { sub-continent } \\
\text { (India, Bangladesh } \\
\text { or Pakistan) }\end{array}$} & \multirow[t]{2}{*}{ No } & Scr. uptake: NR & \multirow[t]{2}{*}{ Not applicable } & \multirow[t]{2}{*}{ Not applicable } \\
\hline & & & & & & & & & $\begin{array}{l}\text { Prevalence: 0\% } \\
(0 / 171 ; 95 \% \mathrm{Cl}: \\
0-2.19)^{* *}\end{array}$ & & \\
\hline \multirow[t]{2}{*}{$\begin{array}{l}\text { Kallman et al. } \\
2010 \text { [47] }^{\mathrm{a}}\end{array}$} & \multirow[t]{2}{*}{ NR } & \multirow[t]{2}{*}{ GP patients } & \multirow[t]{2}{*}{$\begin{array}{l}\text { USA (1.9\%): } \\
\text { Northern } \\
\text { Virginia }\end{array}$} & \multirow[t]{2}{*}{$\begin{array}{l}\text { GP clinic (and } \\
\text { general health } \\
\text { screening at } \\
\text { Asian health } \\
\text { fairs, see } \\
\text { Additional file } \\
\text { 1: Table S1) }\end{array}$} & \multirow[t]{2}{*}{$N R$} & \multirow[t]{2}{*}{ HBV } & \multirow[t]{2}{*}{$\begin{array}{l}\text { Yes, } \\
\text { Vietnamese }\end{array}$} & \multirow[t]{2}{*}{$N R$} & $\begin{array}{l}\text { Scr. uptake: NR } \\
\text { Prevalence: 1.2\% } \\
\text { (3/245; 95\% Cl: } \\
0.4-3.5) \text { at GP } \\
\text { clinic** }^{* *}\end{array}$ & \multirow[t]{2}{*}{$\begin{array}{l}\text { Univariable regr. } \\
\text { analysis: } \\
\text { - Elevated AST }\end{array}$} & $\begin{array}{l}\text { Patients were seen } \\
\text { by their primary care } \\
\text { givers for further } \\
\text { management, or } \\
\text { referred for further } \\
\text { follow-up and } \\
\text { treatment (no results } \\
\text { reported). }\end{array}$ \\
\hline & & & & & & & & & & & $\begin{array}{l}\text { Outcomes: } \\
\text { RNA rate: NR } \\
\text { Start treatment: NR } \\
\text { SVR: NR }\end{array}$ \\
\hline \multirow[t]{2}{*}{$\begin{array}{l}\text { Ouzan, D, } \\
2003 \text { [72] }\end{array}$} & \multirow[t]{2}{*}{2000} & \multirow[t]{2}{*}{$\begin{array}{l}\text { GP patients } \\
\text { aged over } \\
18 \text { years }\end{array}$} & \multirow[t]{2}{*}{$\begin{array}{l}\text { France (1.1\%): } \\
\text { Alpes- } \\
\text { Maritimes } \\
\text { district }\end{array}$} & \multirow[t]{2}{*}{ GP clinic } & \multirow[t]{2}{*}{1 month } & \multirow[t]{2}{*}{ None } & \multirow{2}{*}{$\begin{array}{l}\text { Yes: unknown } \\
\text { HCV serology } \\
\text { status, and at } \\
\text { least one risk } \\
\text { factor: blood } \\
\text { transfusion } \\
\text { before 1991, } \\
\text { injecting or } \\
\text { nasal DU, } \\
\text { incarceration. } \\
\text { Previously } \\
\text { diagnosed HCV } \\
\text { positives that } \\
\text { visited the GP in } \\
\text { the screening } \\
\text { period were } \\
\text { also followed- } \\
\text { up. }\end{array}$} & \multirow{2}{*}{ No } & \multirow{2}{*}{$\begin{array}{l}\text { Scr. uptake: } \\
66.0 \% \text { (233/353) } \\
\text { Prevalence:3.9\% } \\
\text { (9/233; 95\% Cl: } \\
\text { 2.0-7.02) } 9 \text { were } \\
\text { newly identified } \\
\text { through } \\
\text { screening; } 229 \\
\text { were found with } \\
\text { a previous } \\
\text { diagnosis** }\end{array}$} & \multirow[t]{2}{*}{$\begin{array}{l}\text { NR for newly } \\
\text { identified }\end{array}$} & $\begin{array}{l}\text { Patients were } \\
\text { followed-up by their } \\
\text { GP, referred to a } \\
\text { specialist, or a } \\
\text { hospital unit. }\end{array}$ \\
\hline & & & & & & & & & & & $\begin{array}{l}\text { Follow-up data are } \\
\text { reported for newly } \\
\text { and previously } \\
\text { diagnosed patients } \\
\text { together and } \\
\text { available for } 159 \text { / } \\
238 \text {. HCV RNA test } \\
\text { results were known } \\
\text { for } n=106 \text {, and } \\
82 \text { were HCV } \\
\text { RNA positive. A } \\
\text { liver biopsy } \\
\text { was performed } \\
\text { in } 62 \text {, of which } \\
31 \text { received } \\
\text { treatment. } \\
\text { Treatment was } \\
\text { effective for } 10, \\
\text { fairly effective } \\
\text { for } 12 \text {, and } \\
\text { ineffective for } 7 \text {. }\end{array}$ \\
\hline
\end{tabular}




\begin{tabular}{|c|c|c|c|c|c|c|c|c|c|c|c|}
\hline \multirow{3}{*}{$\begin{array}{l}\text { Pradat et al. } \\
2001 \text { [74] }\end{array}$} & \multirow{3}{*}{1997} & \multirow{3}{*}{$\begin{array}{l}\text { GP patients } \\
\text { aged } 18-69 \text { yrs }\end{array}$} & \multirow{3}{*}{$\begin{array}{l}\text { France }(1.1 \%): \\
\text { Lyon area }\end{array}$} & \multirow{3}{*}{ GP clinics } & \multirow{3}{*}{$\begin{array}{l}6 \text { months; } \\
\text { each GP clinic } \\
\text { offered HCV } \\
\text { screening } \\
\text { for } 5 \text { days }\end{array}$} & \multirow{3}{*}{ None } & \multirow{3}{*}{ No } & \multirow{3}{*}{ NR } & & & \\
\hline & & & & & & & & & $\begin{array}{l}\text { Scr. uptake: 59.0\% } \\
6876 / 11646\end{array}$ & \multirow{2}{*}{$\begin{array}{l}\text { Listed risk factors: } \\
\text { - History of IDU } \\
\text { - Transfusion <1990 } \\
\text { - Other risk factors }\end{array}$} & \multirow{2}{*}{$\begin{array}{l}\text { NR } \\
\text { Outcomes: } \\
\text { RNA rate: NR } \\
\text { Start treatment: NR } \\
\text { SVR: NR }\end{array}$} \\
\hline & & & & & & & & & $\begin{array}{l}\text { Prevalence: } \\
\text { 0.4\% (30/6876; } \\
95 \% \text { Cl: 0.3-0.6)*** }\end{array}$ & & \\
\hline \multirow{3}{*}{$\begin{array}{l}\text { Altman et al. } \\
1999 \text { [75] }\end{array}$} & \multirow[t]{3}{*}{1997} & \multirow[t]{3}{*}{ GP patients } & \multirow{3}{*}{$\begin{array}{l}\text { France (1.1\%): } \\
\text { Val-de-Marne } \\
\text { and Hauts- } \\
\text { de-Seine }\end{array}$} & \multirow{3}{*}{ GP clinics } & \multirow[t]{3}{*}{2 weeks } & \multirow[t]{3}{*}{ None } & \multirow{3}{*}{$\begin{array}{l}\text { Yes, no } \\
\text { previous HCV } \\
\text { serology } \\
\text { performed, } \\
\text { and a history } \\
\text { of IDU or } \\
\text { transfusion } \\
\text { before } 1991\end{array}$} & \multirow[t]{3}{*}{ No } & Scr. uptake: & \multirow[t]{3}{*}{$N R$} & NR \\
\hline & & & & & & & & & $\begin{array}{l}\text { Transfusion } \\
\text { group: } 76.9 \% \\
\text { (226/294) } \\
\text { History of IDU } \\
\text { group: } 50.0 \% \\
\text { (13/26) }\end{array}$ & & $\begin{array}{l}\text { Outcomes: } \\
\text { RNA rate: NR } \\
\text { Start treatment: } \\
\text { NR } \\
\text { SVR: NR }\end{array}$ \\
\hline & & & & & & & & & $\begin{array}{l}\text { Prevalence: } \\
\text { Transfusion } \\
\text { group: } 3.1 \% \text { (7/ } \\
\text { 226, 95\% Cl: 1.5- } \\
6.3 \text { ) } \\
\text { History of IDU } \\
\text { group: 30.8\% (4/ } \\
\text { 13; 95\% Cl: } 12.7- \\
\text { 57.6)* }\end{array}$ & & \\
\hline \multirow{2}{*}{$\begin{array}{l}\text { Helsper et al. } \\
2010 \text { [76] }\end{array}$} & \multirow[t]{2}{*}{$2007-2008$} & \multirow[t]{2}{*}{ GP patients } & \multirow{2}{*}{$\begin{array}{l}\text { Netherlands } \\
(1.1 \%) \text { : } \\
\text { Amersfoort } \\
\text { and } \\
\text { Apeldoorn }\end{array}$} & \multirow[b]{2}{*}{$\begin{array}{l}\text { GP clinics in } \\
\text { intervention } \\
\text { region with } \\
\text { primary care } \\
\text { practice } \\
\text { support, and } \\
\text { GP clinics in } \\
\text { control region } \\
\text { without } \\
\text { practice }\end{array}$} & \multirow[t]{2}{*}{4 months } & \multirow[t]{2}{*}{ None } & \multirow{2}{*}{$\begin{array}{l}\text { Yes, individual } \\
\text { risk estimation } \\
\text { by GP }\end{array}$} & \multirow[t]{2}{*}{ Yes } & Scr. uptake: NR & \multirow[t]{2}{*}{ Data not available } & NR \\
\hline & & & & & & & & & $\begin{array}{l}\text { Prevalence: } \\
\text { Intervention: } \\
\text { 1.7\% (3/172; } \\
95 \% \text { Cl: 0.6-5.0) } \\
\text { Control: 0.8\% (1/ } \\
\text { 118; 95\% Cl: } \\
0.04-4.6)^{* *}\end{array}$ & & $\begin{array}{l}\text { Outcomes: } \\
\text { RNA rate: NR } \\
\text { Start treatment: NR } \\
\text { SVR: NR }\end{array}$ \\
\hline
\end{tabular}


Table 3 Integrated screening programs at general practitioner (GP) clinics (Continued)

\begin{tabular}{|c|c|c|c|c|c|c|c|c|c|c|c|}
\hline \multirow{2}{*}{$\begin{array}{l}\text { Sahajian et al. } \\
2004 \text { [77] }\end{array}$} & \multirow[t]{2}{*}{ 2000-2001 } & \multirow{2}{*}{$\begin{array}{l}\text { GP, private } \\
\text { practitioners, } \\
\text { and specialist } \\
\text { patients }\end{array}$} & \multirow{2}{*}{$\begin{array}{l}\text { France (1.1\%): } \\
\text { Lyon area }\end{array}$} & \multirow[b]{2}{*}{$\begin{array}{l}\text { GP clinics } \\
\text { Intervention: A } \\
\text { campaign } \\
\text { including } \\
\text { training aimed } \\
\text { at GPs was } \\
\text { designed to } \\
\text { improve } \\
\text { screening } \\
\text { practices. The } \\
\text { campaign also } \\
\text { reached the } \\
\text { public. } \\
\text { Comparison: } \\
\text { Data were } \\
\text { compared to } \\
\text { the 12-months } \\
\text { period preced- } \\
\text { ing the } \\
\text { campaign. }\end{array}$} & \multirow[b]{2}{*}{12 months } & \multirow[t]{2}{*}{ None } & \multirow[b]{2}{*}{$\begin{array}{l}\text { Yes, history of } \\
\text { IDU, blood } \\
\text { products } \\
\text { before 1991, } \\
\text { or elevated } \\
\text { serum } \\
\text { transaminase } \\
\text { levels }\end{array}$} & \multirow[t]{2}{*}{ Yes } & Scr. uptake: NR & \multirow[t]{2}{*}{ NR } & \multirow{2}{*}{$\begin{array}{l}\text { NR } \\
\text { Outcomes: } \\
\text { RNA rate: NR } \\
\text { Start treatment: NR } \\
\text { SVR: NR }\end{array}$} \\
\hline & & & & & & & & & $\begin{array}{l}\text { Prevalence: } \\
\text { Intervention: } \\
\text { 1.73\% (276/ } \\
15952 ; 95 \% \text { Cl: } \\
\text { 1.53-1.94) } \\
\text { Comparison: } \\
\text { 1.67\% (231/ } \\
\text { 13799; 95\% } \\
\text { Cl:1.47-1.90)** }\end{array}$ & & \\
\hline $\begin{array}{l}\text { Roudot- } \\
\text { Thoraval et al. } \\
2000 \text { [78] }\end{array}$ & 1997-1998 & $\begin{array}{l}\text { GP patients } \\
\text { aged } \\
6-85 \text { years }\end{array}$ & $\begin{array}{l}\text { France (1.1\%): } \\
\text { Le Doubs } \\
\text { and } n^{\circ} 6 \\
\text { d'lle-de- }^{\circ} \\
\text { France }\end{array}$ & $\begin{array}{l}\text { GP clinics } \\
\text { Intervention 1: } \\
\text { GPs asked } \\
\text { their patients } \\
\text { for risk factors } \\
\text { for HCV and } \\
\text { offered } \\
\text { screening to } \\
\text { those at risk. } \\
\text { Intervention 2: } \\
\text { Posters and } \\
\text { leaflets in GPs } \\
\text { waiting } \\
\text { rooms, } \\
\text { motivating } \\
\text { those with a } \\
\text { risk to discuss } \\
\text { testing with } \\
\text { their GP. }\end{array}$ & 15 months & None & $\begin{array}{l}\text { Yes, several } \\
\text { risk factors } \\
\text { (not all are } \\
\text { listed), among } \\
\text { which a } \\
\text { history of IDU, } \\
\text { transfusion, } \\
\text { tattoo, HCV in } \\
\text { social } \\
\text { environment }\end{array}$ & $\begin{array}{l}\text { Yes } \\
\text { (intervention } \\
\text { 2) }\end{array}$ & $\begin{array}{l}\text { Scr. uptake: NR } \\
\text { Prevalence: } \\
\text { Intervention 1: } \\
5.7 \% \text { (15/261; } \\
95 \% \text { Cl: 3.51- } \\
9.26) \\
\text { Intervention 2: } \\
4.4 \%(10 / 228 ; \\
95 \% \text { Cl: } 2.40- \\
7.88)^{* *}\end{array}$ & $\begin{array}{l}\text { Listed risk factors: } \\
\text { - History of IDU } \\
\text { - Transfusion before } \\
1991 \text { - Elevated ALT } \\
\text { or symptoms } \\
\text { - Tattoo } \\
\text { - Other }\end{array}$ & $\begin{array}{l}\text { NR } \\
\text { Outcomes: } \\
\text { RNA rate: NR } \\
\text { Start treatment: NR } \\
\text { SVR: }\end{array}$ \\
\hline $\begin{array}{l}\text { Note: } \mathrm{Cl}=\text { confid } \\
\text { aminotransferas } \\
\text { *HCV-antibody } \\
\text { **The reliability o } \\
\text { ***HCV-antibody } \\
\text { (RIBA), Innogene } \\
\text { alThe program } \\
\text { b } \\
\text { 'Médecins du M } \\
\text { 'Transfusion bef } \\
\text { procedures (catt }\end{array}$ & $\begin{array}{l}\text { dence interval; } \\
\text { se; SVR = sustair } \\
\text { prevalence is C } \\
\text { of the reported } \\
\text { y prevalence is } \\
\text { etics (LiaTek), P } \\
\text { is combined a } \\
\text { Monde ('Doctor } \\
\text { fore 1991, histc } \\
\text { heterism, fluid }\end{array}$ & $\begin{array}{l}\text { onsidered subopt } \\
\text { HCV-antibody prev } \\
\text { considered valid; } \\
\text { asteur (DECISCAN } \\
\text { honintegrated scr } \\
\text { of the World') is } \\
\text { ry of drug use, hi }\end{array}$ & $\begin{array}{l}\text { a were collected } \\
\text { V), Genelabs Dia } \\
\text { ing approach wi } \\
\text { international hu } \\
\text { y of gastroscopy }\end{array}$ & $\begin{array}{l}\text { ug use; } \mathrm{HCV}=\text { hepe } \\
\text { lected before } 1994 \\
\text { (data were collecte } \\
\text { d after 1993, and r } \\
\text { agnostics (HCV BLC } \\
\text { ith integrated scre } \\
\text { manitarian organiz } \\
\text { y, contact with HC }\end{array}$ & $\begin{array}{l}d \text { after } 1993, b \\
\text { eactive HCV-a } \\
\text { DT), or Mikrog } \\
\text { ening at the C } \\
\text { zation providir } \\
V \text { infected per } \\
\text { tory of surgen }\end{array}$ & $\begin{array}{l}\text { dy test } \\
\text { ecomBl } \\
\text { nic (see } \\
\text { edical } \\
\text { spouse }\end{array}$ & $\begin{array}{l}\text { ty of tests was not } \\
\text { ostic tests are unspe } \\
\text { results were confi } \\
\text { ot HCV IgG 2.0). } \\
\text { Additional file 1: } \\
\text { care to vulnerable } \\
\text { or other family } \mathrm{m}\end{array}$ & $\begin{array}{l}\text { timal, or reacti } \\
\text { ed, or other tha } \\
\text { ed by second c } \\
\text { le S1). Here on } \\
\text { ulations. } \\
\text { ber, occupatior }\end{array}$ & $\begin{array}{l}\text { ve HCV-antibody t } \\
\text { in described below, } \\
\text { or higher generatio } \\
\text { ly results of the in } \\
\text { nal exposure, activ }\end{array}$ & $\begin{array}{l}\text { nine aminotransferase; } \\
\text { results were not confirn } \\
\text { dried blood spots or oral } \\
\text { nmunoblot assays from } \\
\text { rated screening are pre } \\
\text { former imprisonment, }\end{array}$ & $\begin{array}{l}\text { T = aspartate } \\
\text { d by immunoblot). } \\
\text { id samples were used). } \\
\text { rtho, Chiron, Novartis } \\
\text { ted. } \\
\text { tory of invasive }\end{array}$ \\
\hline
\end{tabular}

procedures (catheterism, fluid aspiration/cytology, biopsy), history of colonoscopy, history of surgery. 
Table 4 Integrated screening programs at VA clinics

\begin{tabular}{|c|c|c|c|c|c|c|c|c|c|c|c|}
\hline \multicolumn{9}{|c|}{ Program characteristics } & \multicolumn{3}{|c|}{ Program outcomes } \\
\hline $\begin{array}{l}\text { First author, } \\
\text { year of } \\
\text { publication }\end{array}$ & $\begin{array}{l}\text { Calendar } \\
\text { year of data } \\
\text { collection }\end{array}$ & Population & $\begin{array}{l}\text { Country } \\
\text { and HCV } \\
\text { prevalence } \\
\text { according } \\
\text { to CDC [23] }\end{array}$ & $\begin{array}{l}\text { Setting of } \\
\text { screening }\end{array}$ & $\begin{array}{l}\text { Duration of } \\
\text { screening } \\
\text { program }\end{array}$ & $\begin{array}{l}\text { Other } \\
\text { tests }\end{array}$ & $\begin{array}{l}\text { Prescreening } \\
\text { selection }\end{array}$ & $\begin{array}{l}\text { Media } \\
\text { activities }\end{array}$ & $\begin{array}{l}\text { Screening } \\
\text { uptake and } \\
\text { anti-HCV } \\
\text { prevalence } \\
(95 \% \mathrm{Cl})\end{array}$ & $\begin{array}{l}\text { Risk profile } \\
\text { of identified } \\
\text { HCV cases/ } \\
\text { Risk factors } \\
\text { associated } \\
\text { with HCV }\end{array}$ & $\begin{array}{l}\text { Follow-up of HCV-infected } \\
\text { individuals }\end{array}$ \\
\hline \multirow{3}{*}{$\begin{array}{l}\text { Groom et al. } \\
2008 \text { [79] }\end{array}$} & \multirow[t]{3}{*}{$2000-2001$} & \multirow[t]{3}{*}{ Veterans } & \multirow{3}{*}{$\begin{array}{l}\text { USA (1.9\%): } \\
\text { Minneapolis }\end{array}$} & \multirow{3}{*}{$\begin{array}{l}\text { Veteran } \\
\text { Affairs clinic }\end{array}$} & \multirow[t]{3}{*}{2 years } & \multirow[t]{3}{*}{ None } & \multirow{3}{*}{$\begin{array}{l}\text { Yes, only those } \\
\text { with a risk factor } \\
\text { were screened } \\
\text { (risk factors } \\
\text { not specified) }\end{array}$} & \multirow[t]{3}{*}{ NR } & Scr. uptake: NR & \multirow[t]{3}{*}{ NR } & \multirow[b]{2}{*}{$\begin{array}{l}\text { In total, 520/681 were HCV RNA } \\
\text { positive of which } 430 \text { referred to } \\
\text { a specialist, of which } 88.8 \% \\
\text { (382/430) attended an } \\
\text { appointment. Of those, } 32.5 \% \\
\text { (124/382) received treatment } \\
\text { which was successful in } 37.0 \% \\
\text { (46/124) (SVR). }\end{array}$} \\
\hline & & & & & & & & & \multirow[t]{2}{*}{$\begin{array}{l}\text { Prevalence: } 5.5 \% \\
(681 / 12485 ; 95 \% \\
\text { Cl: } 5.1-5.9)^{*}\end{array}$} & & \\
\hline & & & & & & & & & & & $\begin{array}{l}\text { Outcomes: } \\
\text { RNA rate: } 76.4 \%(520 / 681) \\
\text { Start treatment: } 32.5 \%(124 / 382) \\
\text { SVR: } 37.1 \%(46 / 124)\end{array}$ \\
\hline $\begin{array}{l}\text { Mallette et al. } \\
2008 \text { [80] }\end{array}$ & 1998-2004 & Veterans & $\begin{array}{l}\text { USA (1.9\%): } \\
\text { Providence }\end{array}$ & $\begin{array}{l}\text { GP patients } \\
\text { presenting } \\
\text { to VA clinics }\end{array}$ & $\begin{array}{l}5 \text { years and } \\
8 \text { months }\end{array}$ & None & $\begin{array}{l}\text { Yes, only those } \\
\text { with a risk factor } \\
\text { were screened }\end{array}$ & NR & $\begin{array}{l}\text { Scr. uptake: } \\
66.7 \% \text { (5646/ } \\
8471) \\
\text { Prevalence: } 7.3 \% \\
\text { (412/5646; } 95 \% \\
\text { Cl: 6.6-8.0); without } \\
\text { already known } \\
\text { positives: } 260 / \\
5646=4.6 \%(95 \% \\
C l=4.1-5.2 \%)^{* * *}\end{array}$ & $\begin{array}{l}\text { Listed risk } \\
\text { factors: } \\
\text { - History of } \\
\text { IDU } \\
\text { - Blood } \\
\text { transfusion } \\
\text { before } 1992 \\
\text { - Intranasal } \\
\text { cocaine use } \\
\text { - Multiple } \\
\text { sex partners } \\
\text { - Tattoos }\end{array}$ & $\begin{array}{l}\text { Of the newly diagnosed, } 46.9 \% \\
(122 / 260) \text { had chronic HCV, of } \\
\text { which } 46.7 \% \text { ( } 57 / 122) \text { were } \\
\text { treatment eligible. Of those, } \\
31.6 \%(18 / 57) \text { received } \\
\text { treatment and 33.3\% (6/18) } \\
\text { reached an SVR. } \\
\text { Outcomes: } \\
\text { RNA rate: } 46.9 \%(122 / 260) \\
\text { Start treatment: } 14.8 \%(18 / 122) \\
\text { SVR: } 33.3 \%(6 / 18)\end{array}$ \\
\hline \multirow{3}{*}{$\begin{array}{l}\text { Cheung et al. } \\
2006 \text { [81] }\end{array}$} & \multirow[t]{3}{*}{$2000-2001$} & \multirow[t]{3}{*}{ Veterans } & \multirow{3}{*}{$\begin{array}{l}\text { USA (1.9\%): } \\
\text { Palo Alto }\end{array}$} & \multirow[t]{3}{*}{ VA clinic } & \multirow[t]{3}{*}{12 months } & \multirow[t]{3}{*}{ None } & \multirow{3}{*}{$\begin{array}{l}\text { Yes, } \\
\text { if not previously } \\
\text { tested, and if one } \\
\text { or more risk } \\
\text { factors } \\
\text { were reported }^{b}\end{array}$} & \multirow[t]{3}{*}{ NR } & Scr. uptake: NR & \multirow[t]{3}{*}{ NR } & \multirow[b]{2}{*}{$\begin{array}{l}\text { In total, } 362 / 536 \text { patients were } \\
\text { evaluated of which } 84.8 \% \text { (307/ } \\
362 \text { ) had chronic HCV. Of those, } \\
\text { 18.6\% (57/307) were treatment } \\
\text { eligible of whom } 24.6 \% \text { (14/57) } \\
\text { completed treatment with long- } \\
\text { term follow-up, and } 35.7 \% \\
\text { (5/14) achieved SVR. }\end{array}$} \\
\hline & & & & & & & & & \multirow[t]{2}{*}{$\begin{array}{l}\text { Prevalence: } 5.0 \% \\
(536 / 10751 ; 95 \% \\
\text { Cl: } 4.6-5.4)^{* * *}\end{array}$} & & \\
\hline & & & & & & & & & & & $\begin{array}{l}\text { Outcomes: } \\
\text { RNA rate: } 84.8 \% \text { (307/362) } \\
\text { Start treatment: NR } \\
\text { SVR: } 35.7 \%(5 / 14)\end{array}$ \\
\hline $\begin{array}{l}\text { Rifai et al. } \\
2006 \text { [82] }\end{array}$ & $2000-2001$ & Veterans & $\begin{array}{l}\text { USA (1.9\%): } \\
\text { Virginia }\end{array}$ & $\begin{array}{l}\text { Rural VA } \\
\text { clinic }\end{array}$ & 22 months & None & $\begin{array}{l}\text { Yes, only non-IDU } \\
\text { substance using } \\
\text { veterans who were } \\
\text { admitted to a } \\
\text { substance-use }\end{array}$ & NR & $\begin{array}{l}\text { Scr. uptake: } \\
\text { 99.4\% (338/340) } \\
\\
\text { Prevalence: 23.1\% } \\
\text { CHCV (78/338; }\end{array}$ & $\begin{array}{l}\text { Univariate } \\
\text { regr. analysis: } \\
\text { - Cocaine } \\
\text { snorting }\end{array}$ & $\begin{array}{l}\text { In total, } 48.7 \%(38 / 78) \text { of the } \\
\text { patients remained abstinent for } 6 \\
\text { months and } 30 \text { were indicated for } \\
\text { treatment and received treatment. }\end{array}$ \\
\hline
\end{tabular}


Table 4 Integrated screening programs at VA clinics (Continued)

\begin{tabular}{|c|c|c|c|c|c|c|c|c|c|c|c|}
\hline & & & & & & & \multirow{2}{*}{\multicolumn{2}{|c|}{$\begin{array}{l}\text { residential and } \\
\text { rehabilitation } \\
\text { treatment } \\
\text { program } \\
\text { were tested }\end{array}$}} & \multirow{2}{*}{$\begin{array}{l}\text { 95\% Cl: 18.9-27.9) } \\
\text { (incl. } 2 \text { who knew } \\
\text { already)**** }\end{array}$} & \multirow[t]{2}{*}{$\begin{array}{l}\text { - History of } \\
\text { IDU }\end{array}$} & $\begin{array}{l}\text { In } 46.7 \%(14 / 30) \text { treatment was } \\
\text { successful (SVR). }\end{array}$ \\
\hline & & & & & & & & & & & $\begin{array}{l}\text { Outcomes: } \\
\text { RNA rate: n/a } \\
\text { Start treatment: 81.1\% (30/37) } \\
\text { SVR: } 46.7 \%(14 / 30)\end{array}$ \\
\hline $\begin{array}{l}\text { Zuniga et al. } \\
2006 \text { (abstract) } \\
\text { [83] }\end{array}$ & 2001-2003 & Veterans & $\begin{array}{l}\text { USA (1.9\%): } \\
\text { Suffolk } \\
\text { County, } \\
\text { Long Island }\end{array}$ & $\begin{array}{l}\text { Primary-care } \\
\text { outpatient } \\
\text { departments } \\
\text { of the } \\
\text { Northport VA } \\
\text { clinic } \\
\text { (suburban } \\
\text { VA hospital) }\end{array}$ & 27 months & None & $\begin{array}{l}\text { Yes, only those } \\
\text { with a risk } \\
\text { factor were } \\
\text { screened }^{c}\end{array}$ & No & $\begin{array}{l}\text { Scr. uptake: } \\
41.9 \% \text { (2263/ } \\
5400) \\
\\
\text { Prevalence: } 4.6 \% \\
\text { CHCV (103/2263; } \\
95 \% \text { Cl: 3.8-5.5) })^{* * * *}\end{array}$ & $\begin{array}{l}\text { Multivariable } \\
\text { regr. analysis } \\
\text { - Age 40- } \\
54 \text { yrs } \\
\text { - Black race } \\
\text { - History of IDU } \\
\text { - Service } \\
\text { during } \\
\text { Vietnam era } \\
\text { - Blood } \\
\text { transfusion } \\
\text { prior to 1992 } \\
\text { - Tattoo or } \\
\text { repeated } \\
\text { body } \\
\text { piercing } \\
\text { - History of } \\
\text { abnormal } \\
\text { LFTs }\end{array}$ & $\begin{array}{l}\text { NR } \\
\text { Outcomes: } \\
\text { RNA rate: n/a } \\
\text { Start treatment: NR } \\
\text { SVR: NR } \\
\end{array}$ \\
\hline
\end{tabular}

Note: $\mathrm{Cl}$ = confidence interval; $\mathrm{NR}=$ not reported; $\mathrm{VA}=$ veterans affairs; IDU = injecting drug use; $\mathrm{HCV}=$ hepatitis $\mathrm{C}$ virus; $\mathrm{CHCV}=$ chronic hepatitis $\mathrm{C}$ virus; $\mathrm{HIV}=$ human immunodeficiency virus; $\mathrm{LFT}=$ liver function test; $\mathrm{SVR}=$ sustained virological response; $\mathrm{PCR}=$ polymerase chain reaction

*HCV-antibody prevalence is considered suboptimal (data were collected before 1994 when sensitivity/specificity of tests was not optimal, or reactive HCV-antibody test results were not confirmed by immunoblot). ***HCV-antibody prevalence is considered valid; data were collected after 1993, and reactive HCV-antibody test results were confirmed by second or higher generation immunoblot assays from Ortho, Chiron, Novartis (RIBA), Innogenetics (LiaTek), Pasteur (DECISCAN HCV), Genelabs Diagnostics (HCV BLOT), or Mikrogen (recomBlot HCV IgG 2.0).

****HCV-antibody prevalence is considered valid, but reflecting chronic HCV infection (data were collected after 1993, and reactive HCV antibody test results were confirmed by PCR).

${ }^{a}$ Vietnam-era veteran, transfusion of blood of blood products before 1992, history of IDU, history of snorting cocaine, history of 5 or more drinks a day for 10 or more years in your lifetime, history of multiple (10 or more) sexual partners in your lifetime, a man who has sex with men, history of exposure to blood on skin or mucous membranes, required chronic hemodialysis, have a tattoo or body piercing, have had a positive test for HIV or hepatitis B, have been told that you have unexplained liver disease.

bBlood transfusion prior to 1992, IV drug use (even once), snorting of cocaine, blood exposure, sexual promiscuity (>10 lifetime sex partners), renal dialysis, tattoo or body piercing, excessive alcohol use.

'Vietnam-era veteran, transfusion of blood products prior to 1992, history of IDU, blood exposure in or through skin or mucous membranes, multiple sexual partners (past or present), hemodialysis, tattoo or repeated body

piercing, intranasal cocaine use (past or present), unexplained liver disease, having been told that he/she has abnormal liver function tests, intemperate alcohol use (more than seven alcoholic beverages per week). 
Table 5 Integrated screening programs in antenatal/obstetric/fertility clinics

\begin{tabular}{|c|c|c|c|c|c|c|c|c|c|c|c|}
\hline \multicolumn{9}{|c|}{ Program characteristics } & \multicolumn{3}{|c|}{ Program outcomes } \\
\hline $\begin{array}{l}\text { First author, } \\
\text { year of } \\
\text { publication }\end{array}$ & $\begin{array}{l}\text { Calendar } \\
\text { year of data } \\
\text { collection }\end{array}$ & Population & $\begin{array}{l}\text { Country and } \\
\text { HCV prevalence } \\
\text { according to } \\
\text { CDC }[23]\end{array}$ & $\begin{array}{l}\text { Setting of } \\
\text { screening }\end{array}$ & $\begin{array}{l}\text { Duration of } \\
\text { screening } \\
\text { program }\end{array}$ & Other tests & $\begin{array}{l}\text { Prescreening } \\
\text { selection }\end{array}$ & $\begin{array}{l}\text { Media } \\
\text { activities }\end{array}$ & $\begin{array}{l}\text { Screening } \\
\text { uptake and } \\
\text { anti-HCV } \\
\text { prevalence } \\
(95 \% \mathrm{Cl})\end{array}$ & $\begin{array}{l}\text { Risk profile } \\
\text { of identified } \\
\text { HCV cases/ } \\
\text { Risk factors } \\
\text { associated } \\
\text { with HCV }\end{array}$ & $\begin{array}{l}\text { Follow-up of } \\
\text { HCV-infected } \\
\text { individuals }\end{array}$ \\
\hline \multirow{3}{*}{$\begin{array}{l}\text { Alexanian et al. } \\
2009 \text { [84] }\end{array}$} & \multirow[t]{3}{*}{ NR } & \multirow{3}{*}{$\begin{array}{l}\text { Pregnant } \\
\text { women }\end{array}$} & \multirow{3}{*}{$\begin{array}{l}\text { UK (1.1\%): } \\
\text { London }\end{array}$} & \multirow{3}{*}{$\begin{array}{l}\text { Antenatal } \\
\text { clinic }\end{array}$} & \multirow{3}{*}{$\begin{array}{l}8 \text { years, Hospital } \\
\text { records search }\end{array}$} & \multirow{3}{*}{ HBV, HIV } & \multirow[t]{3}{*}{ No } & \multirow[t]{3}{*}{ NR } & Scr. uptake: NR & \multirow[t]{3}{*}{ NR } & \multirow[b]{2}{*}{$\begin{array}{l}\text { In total, } 73.0 \%(84 / 115) \\
\text { of patients had chronic } \\
\text { HCV, of whom } 55.9 \% \\
\text { (47/84) were lost to } \\
\text { follow-up, } 10.7 \%(9 / 84) \\
\text { deferred treatment, } \\
4.8 \%(4 / 84) \text { were on } \\
\text { treatment, and } 17.9 \% \\
(15 / 84) \text { completed } \\
\text { treatment. Of these } 15 \text {, } \\
12 \text { achieved SRV, } 1 \\
\text { relapsed, and two failed } \\
\text { to respond. }\end{array}$} \\
\hline & & & & & & & & & \multirow[t]{2}{*}{$\begin{array}{l}\text { Prevalence: } \\
0.4(115 / \\
31081 ; 95 \% \\
\text { Cl: } 0.3-0.4)^{*}\end{array}$} & & \\
\hline & & & & & & & & & & & $\begin{array}{l}\text { Outcomes: } \\
\text { RNA rate: } 73.0 \%(84 / 115) \\
\text { Start treatment: } 67.9 \% \\
\text { (19/28) } \\
\text { SVR: } 80.0 \%(12 / 15)\end{array}$ \\
\hline \multirow[t]{2}{*}{$\begin{array}{l}\text { Abusheikha et al. } \\
1999 \text { [85] }\end{array}$} & \multirow[t]{2}{*}{ 1996-1998 } & \multirow{2}{*}{$\begin{array}{l}\text { Couples } \\
\text { receiving } \\
\text { fertility } \\
\text { treatment }\end{array}$} & \multirow[t]{2}{*}{$\begin{array}{l}\text { UK (1.1\%): } \\
\text { Cambridge }\end{array}$} & \multirow{2}{*}{$\begin{array}{l}\text { Bourn Hall } \\
\text { clinic, infertility } \\
\text { hospital }\end{array}$} & \multirow{2}{*}{3 years } & \multirow[t]{2}{*}{ HIV, HBV } & \multirow[t]{2}{*}{ No } & \multirow[t]{2}{*}{ NR } & $\begin{array}{l}\text { Scr. uptake: } \\
\text { NR }\end{array}$ & \multirow[t]{2}{*}{ NR } & \multirow{2}{*}{$\begin{array}{l}\text { All patients were } \\
\text { counseled by senior } \\
\text { medical staff. } \\
\text { Outcomes: } \\
\text { RNA rate: NR } \\
\text { Start treatment: NR } \\
\text { SVR: NR }\end{array}$} \\
\hline & & & & & & & & & $\begin{array}{l}\text { Prevalence: } \\
0.5 \%(9 / \\
1658 ; 95 \% \\
\text { Cl: } 0.3-1.0)^{* *}\end{array}$ & & \\
\hline $\begin{array}{l}\text { Leikin et al. } \\
1994 \text { [86] }\end{array}$ & 1991-1992 & $\begin{array}{l}\text { Pregnant } \\
\text { women who } \\
\text { are at risk } \\
\text { for perinatal } \\
\text { complications }\end{array}$ & $\begin{array}{l}\text { USA (1.9\%): } \\
\text { Valhalla }\end{array}$ & $\begin{array}{l}\text { Hospital } \\
\text { (obstetric) }\end{array}$ & 19,5 months & ALT & No & NR & $\begin{array}{l}\text { Scr. uptake: } \\
\text { NR } \\
\text { Prevalence: } \\
4.6 \%(78 / \\
1700 ; 95 \% \\
\text { Cl: 3.7-5.7)* }\end{array}$ & $\begin{array}{l}\text { Multivariable } \\
\text { regr. analysis: } \\
\text { - History of } \\
\text { IDU } \\
\text { - Other drug } \\
\text { use } \\
\text { - Age }>30 \\
\text { - Incarceration } \\
\text { - Blood } \\
\text { transfusion }\end{array}$ & $\begin{array}{l}\text { In total, } 96.2 \%(75 / 78) \\
\text { of the patients returned } \\
\text { for follow-up. No further } \\
\text { details reported. } \\
\text { Outcomes: } \\
\text { RNA rate: NR } \\
\text { Start treatment: NR } \\
\text { SVR: NR }\end{array}$ \\
\hline $\begin{array}{l}\text { Ward et al. } \\
2000 \text { [87] }\end{array}$ & 1997-1999 & $\begin{array}{l}\text { Pregnant } \\
\text { women }\end{array}$ & $\begin{array}{l}\text { UK (1.1\%): } \\
\text { London }\end{array}$ & $\begin{array}{l}\text { Antenatal } \\
\text { clinic }\end{array}$ & 18 months & HBV & No & Yes & $\begin{array}{l}\text { Scr. uptake: } \\
98.0 \% \text { (4727/ } \\
4825) \\
\\
\text { Prevalence: } \\
0.8 \% \text { (38/ }\end{array}$ & $\begin{array}{l}\text { Univariate } \\
\text { regr. analysis: } \\
\text { - History of } \\
\text { IDU } \\
\text { - HCV-infected } \\
\text { partner }\end{array}$ & $\begin{array}{l}\text { In total, } 71.1 \%(27 / 38) \\
\text { had chronic HCV, and } \\
85.2 \%(23 / 27) \text { were } \\
\text { offered follow-up } \\
\text { appointments so } \\
\text { far. Of those, } 82.6 \%\end{array}$ \\
\hline
\end{tabular}




\begin{tabular}{|c|c|c|c|c|c|c|c|c|c|c|c|}
\hline $\begin{array}{l}\text { Costa et al. } \\
2009 \text { [88] }\end{array}$ & 2004-2005 & $\begin{array}{l}\text { Pregnant } \\
\text { women }\end{array}$ & $\begin{array}{l}\text { Brazil (1\%): } \\
\text { Central Brazil, } \\
\text { Goiania }\end{array}$ & $\begin{array}{l}\text { Antenatal } \\
\text { clinics }\end{array}$ & NR & $\begin{array}{l}\text { HIV and } \\
\text { seven other } \\
\text { infectious } \\
\text { diseases (not } \\
\text { specified) }\end{array}$ & No & NR & $\begin{array}{l}\text { Scr. uptake: } \\
\text { 99.9\% (28561/ } \\
\text { 28576) } \\
\text { Prevalence: } \\
\text { 0.2\% CHCV } \\
(43 / 28561 ; \\
\text { 95\% Cl: } 0.1- \\
\text { 0.2\%)**** }\end{array}$ & $\begin{array}{l}\text { Multivariable } \\
\text { regr. analysis: } \\
\text { - Older age } \\
\text { - >3 pregnancies } \\
\text { (no data on } \\
\text { risk factors } \\
\text { collected) }\end{array}$ & $\begin{array}{l}\text { Patients were referred } \\
\text { for free of cost medical } \\
\text { counseling (no results } \\
\text { reported). } \\
\text { Outcomes: } \\
\text { RNA rate: n/a } \\
\text { Start treatment: NR } \\
\text { SVR: NR }\end{array}$ \\
\hline
\end{tabular}

4729; $95 \% \quad-$ Tattoo $\quad(19 / 23)$ attended for

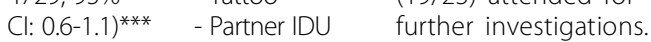

Note: $\mathrm{Cl}=$ confidence interval; $\mathrm{NR}=$ not reported; IDU = injecting drug use; $\mathrm{HCV}=$ hepatitis $\mathrm{C}$ virus; $\mathrm{CHCV}=$ chronic hepatitis $\mathrm{C}$ virus; $\mathrm{HIV}=$ human immunodeficiency virus; $\mathrm{HBV}=$ hepatitis $\mathrm{B}$ virus; $\mathrm{ALT}=$ alanine aminotransferase; SVR = sustained virological response; $\mathrm{PCR}=$ polymerase chain reaction.

*HCV-antibody prevalence is considered suboptimal (data were collected before 1994 when sensitivity/specificity of tests was not optimal, or reactive HCV-antibody test results were not confirmed by immunoblot).

**The reliability of the reported HCV-antibody prevalence is undecided (data were collected after 1993, but the diagnostic tests are unspecified, or other than described below, or dried blood spots or oral fluid samples were used).

***HCV-antibody prevalence is considered valid; data were collected after 1993, and reactive HCV-antibody test results were confirmed by second or higher generation immunoblot assays from Ortho, Chiron, Novartis (RIBA), Innogenetics (LiaTek), Pasteur (DECISCAN HCV), Genelabs Diagnostics (HCV BLOT), or Mikrogen (recomBlot HCV IgG 2.0).

****HCV-antibody prevalence is considered valid, but reflecting chronic HCV infection (data were collected after 1993, and reactive HCV antibody test results were confirmed by PCR). 
Table 6 Integrated screening programs in psychiatric clinics

\begin{tabular}{|c|c|c|c|c|c|c|c|c|c|c|c|}
\hline \multicolumn{9}{|c|}{ Program characteristics } & \multicolumn{3}{|c|}{ Program outcomes } \\
\hline $\begin{array}{l}\text { First author, } \\
\text { year of } \\
\text { publication }\end{array}$ & $\begin{array}{l}\text { Calendar } \\
\text { year of data } \\
\text { collection }\end{array}$ & Population & $\begin{array}{l}\text { Country and } \\
\text { HCV prevalence } \\
\text { according to } \\
\text { CDC [23] }\end{array}$ & $\begin{array}{l}\text { Setting of } \\
\text { screening }\end{array}$ & $\begin{array}{l}\text { Duration of } \\
\text { screening } \\
\text { program }\end{array}$ & $\begin{array}{l}\text { Other } \\
\text { tests }\end{array}$ & $\begin{array}{l}\text { Prescreening } \\
\text { selection }\end{array}$ & $\begin{array}{l}\text { Media } \\
\text { activities }\end{array}$ & $\begin{array}{l}\text { Screening } \\
\text { uptake and } \\
\text { anti-HCV } \\
\text { prevalence } \\
(95 \% \mathrm{Cl})\end{array}$ & $\begin{array}{l}\text { Risk profile of } \\
\text { identified } \\
\text { HCV cases/ } \\
\text { Risk factors } \\
\text { associated } \\
\text { with HCV }\end{array}$ & $\begin{array}{l}\text { Follow-up of HCV-infected } \\
\text { individuals }\end{array}$ \\
\hline \multirow[t]{3}{*}{$\begin{array}{l}\text { Freudenreich, O, } \\
2007 \text { [89] }\end{array}$} & \multirow[t]{3}{*}{ 2003-2004 } & \multirow[t]{3}{*}{$\begin{array}{l}\text { Psychiatric } \\
\text { patients (most } \\
\text { schizophrenia) }\end{array}$} & \multirow[t]{3}{*}{$\begin{array}{l}\text { USA (1.9\%): } \\
\text { Boston }\end{array}$} & \multirow{3}{*}{$\begin{array}{l}\text { Clozapine } \\
\text { outpatient } \\
\text { clinic } \\
\text { (psychiatric } \\
\text { patients) }\end{array}$} & \multirow[t]{3}{*}{4 months } & \multirow[t]{3}{*}{ None } & \multirow[t]{3}{*}{ No } & \multirow[t]{3}{*}{ NR } & $\begin{array}{l}\text { Scr. uptake: } \\
100 \% \\
(98 / 98)\end{array}$ & \multirow{3}{*}{$\begin{array}{l}\text { Most common } \\
\text { risk factors: } \\
\text { - Polysubstance } \\
\text { abuse }\end{array}$} & \multirow{3}{*}{$\begin{array}{l}\text { All patients were referred to a } \\
\text { specialist; after two years, none } \\
\text { had started treatment. One } \\
\text { patient became unstable } \\
\text { psychologically after the } \\
\text { discovery of his infection. }\end{array}$} \\
\hline & & & & & & & & & \multirow{2}{*}{$\begin{array}{l}\text { Prevalence: } \\
8.2 \% \text { (8/98; } \\
95 \% \text { Cl: } 4.2- \\
15.3) \text { (ind the } \\
\text { one known } \\
\text { before)* }\end{array}$} & & \\
\hline & & & & & & & & & & & \\
\hline $\begin{array}{l}\text { Gunewardene, R, } \\
2010 \text { [90] }\end{array}$ & NR & $\begin{array}{l}\text { Psychiatric } \\
\text { patients }\end{array}$ & $\begin{array}{l}\text { Australia (2\%): in } \\
\text { a capital city }\end{array}$ & $\begin{array}{l}\text { Acute } \\
\text { psychiatric } \\
\text { inpatient unit } \\
\text { within an } \\
\text { Area Health } \\
\text { service in } \\
\text { Australia. } \\
\text { Comparison } \\
\text { of two } \\
\text { strategies. }\end{array}$ & 6 months & None & $\begin{array}{l}\text { Unit A: No; } \\
\text { Unit B: Yes (IDU, } \\
\text { exposure to } \\
\text { contaminated } \\
\text { blood products) }\end{array}$ & $N R$ & $\begin{array}{l}\text { Scr. uptake: } \\
\text { Unit A: } 79.8 \% \\
\text { (95/119) } \\
\text { Unit B: } 90.0 \% \\
\text { (36/40) } \\
\text { Prevalence: } \\
\text { Unit A: } 3.2 \% \\
\text { (3/95; } 95 \% \\
\text { Cl: } 1.1-8.9) ;\end{array}$ & $\begin{array}{l}\text { Most common } \\
\text { risk factors: } \\
\text { - History of IDU }\end{array}$ & $\begin{array}{l}\text { All patients were offered } \\
\text { post-test counseling and were } \\
\text { referred to a specialist (no } \\
\text { results reported). } \\
\text { Outcomes: } \\
\text { RNA rate: NR } \\
\text { Start treatment: NR } \\
\text { SVR: NR }\end{array}$ \\
\hline $\begin{array}{l}\text { Lacey, C, } \\
2007[91]\end{array}$ & $2002-2003$ & $\begin{array}{l}\text { Psychiatric } \\
\text { patients }\end{array}$ & $\begin{array}{l}\text { Australia (2\%): } \\
\text { Melbourne, } \\
\text { Victoria }\end{array}$ & $\begin{array}{l}\text { Inner city } \\
\text { public } \\
\text { hospital } \\
\text { (psychiatric) }\end{array}$ & 6 months & None & $\begin{array}{l}\text { Yes; Patients } \\
\text { admitted with } \\
\text { psychotic or } \\
\text { affective disorders, } \\
>18 \text { yrs, inpatient } \\
\text { stay }>2 \text { days, and } \\
\text { did not have } \\
\text { known HCV } \\
\text { infection }\end{array}$ & Yes & $\begin{array}{l}\text { Scr. uptake: } \\
\text { 20.5\% } \\
\text { (71/346) } \\
\text { Prevalence: } \\
\text { 19.7\% (14/71; } \\
\text { 95\% Cl: 12.1- } \\
\text { 30.4)* }\end{array}$ & $\begin{array}{l}\text { Most common } \\
\text { risk factors: } \\
\text { - History of } \\
\text { IDU } \\
\text { - Sharing } \\
\text { injection } \\
\text { equipment }\end{array}$ & $\begin{array}{l}\text { All positive patients received } \\
\text { post-test counseling and were } \\
\text { referred to a specialist (no } \\
\text { results reported). } \\
\text { Outcomes: } \\
\text { RNA rate: NR } \\
\text { Start treatment: NR } \\
\text { SVR: NR }\end{array}$ \\
\hline
\end{tabular}

Note: $\mathrm{Cl}=$ confidence interval; $\mathrm{NR}=$ not reported; IDU = injecting drug use; $\mathrm{HCV}=$ hepatitis $\mathrm{C}$ virus; $\mathrm{SVR}=$ sustained virological response.

*HCV-antibody prevalence is considered suboptimal (data were collected before 1994 when sensitivity/specificity of tests was not optimal, or reactive HCV-antibody test results were not confirmed by immunoblot). ${ }^{*}$ The reliability of the reported HCV-antibody prevalence is undecided (data were collected after 1993, but the diagnostic tests are unspecified, or other than described below (see ***), or dried blood spots or oral fluid samples were used).

***HCV-antibody prevalence is considered valid; data were collected after 1993, and reactive HCV-antibody test results were confirmed by second or higher generation immunoblot assays from Ortho, Chiron, Novartis (RIBA), Innogenetics (LiaTek), Pasteur (DECISCAN HCV), Genelabs Diagnostics (HCV BLOT), or Mikrogen (recomBlot HCV IgG 2.0). 
Table 7 Integrated screening programs integrated in other clinics or services

\begin{tabular}{|c|c|c|c|c|c|c|c|c|c|c|c|}
\hline \multicolumn{9}{|c|}{ Program characteristics } & \multicolumn{3}{|c|}{ Program outcomes } \\
\hline $\begin{array}{l}\text { First author, } \\
\text { year of } \\
\text { publication }\end{array}$ & $\begin{array}{l}\text { Calendar } \\
\text { year of data } \\
\text { collection }\end{array}$ & Population & $\begin{array}{l}\text { Country and } \\
\text { HCV prevalence } \\
\text { according to } \\
\text { CDC [23] }\end{array}$ & $\begin{array}{l}\text { Setting of } \\
\text { screening }\end{array}$ & $\begin{array}{l}\text { Duration of } \\
\text { screening } \\
\text { program }\end{array}$ & $\begin{array}{l}\text { Other } \\
\text { tests }\end{array}$ & $\begin{array}{l}\text { Pre-screening } \\
\text { selection }\end{array}$ & $\begin{array}{l}\text { Media } \\
\text { activities }\end{array}$ & $\begin{array}{l}\text { Screening } \\
\text { uptake and } \\
\text { anti-HCV } \\
\text { prevalence } \\
(95 \% \mathrm{Cl})\end{array}$ & $\begin{array}{l}\text { Risk profile } \\
\text { of identified } \\
\text { HCV cases/ } \\
\text { Risk factors } \\
\text { associated } \\
\text { with HCV }\end{array}$ & $\begin{array}{l}\text { Follow-up of HCV-infected } \\
\text { individuals }\end{array}$ \\
\hline $\begin{array}{l}\text { Capron, D, } \\
1999 \text { [92] }\end{array}$ & 1996 & $\begin{array}{l}\text { Patients }>14 \text { y } \\
\text { admitted to an } \\
\text { emergency unit }\end{array}$ & $\begin{array}{l}\text { France (1.1\%): } \\
\text { Picardy }\end{array}$ & $\begin{array}{l}\text { Emergency } \\
\text { health unit } \\
\text { hospital }\end{array}$ & $\begin{array}{l}\text { At least one } \\
\text { week per } \\
\text { unit ( } 7 \text { units) } \\
\text { over a } \\
\text { period of } 2 \\
\text { months }\end{array}$ & None & $\begin{array}{l}\text { Yes, only } \\
\text { those with a } \\
\text { reported risk } \\
\text { factor were } \\
\text { tested }\end{array}$ & $N R$ & $\begin{array}{l}\text { Scr. uptake: NR } \\
\text { Prevalence: } \\
2.4 \%(11 / \\
451 ; 95 \% \\
\text { Cl: } 1.4-4.3)^{*}\end{array}$ & $\begin{array}{l}\text { Most } \\
\text { common risk } \\
\text { factors: } \\
\text { - Blood } \\
\text { transfusion } \\
\text { - History of } \\
\text { drug } \\
\text { addiction } \\
\text { - Surgery } \\
\text { - Endoscopy }\end{array}$ & $\begin{array}{l}\text { All patients were referred for } \\
\text { medical follow-up. In total, } \\
36.4 \%(4 / 11) \text { attended, of } \\
\text { which } 50.0 \%(2 / 4) \text { had } \\
\text { chronic HCV. Liver biopsy } \\
\text { showed minimal activity, and } \\
\text { treatment was not indicated } \\
\text { Outcomes: } \\
\text { RNA rate: } 50.0 \%(2 / 4) \\
\text { Start treatment: } 0 \%(0 / 2) \\
\text { SVR: - }\end{array}$ \\
\hline \multirow{3}{*}{$\begin{array}{l}\text { Alswaidi, FM, } \\
2010 \text { [93] }\end{array}$} & \multirow[t]{3}{*}{2008} & \multirow{3}{*}{$\begin{array}{l}\text { Individuals from } \\
\text { the general } \\
\text { population that } \\
\text { wish to get } \\
\text { married }\end{array}$} & \multirow{3}{*}{$\begin{array}{l}\text { Saudi Arabia } \\
(0.9 \%) \text { : } \\
\text { throughout the } \\
\text { country }\end{array}$} & \multirow{3}{*}{$\begin{array}{l}\text { Mandatory } \\
\text { premarital } \\
\text { national } \\
\text { screening } \\
\text { program }\end{array}$} & \multirow[t]{3}{*}{4 months } & \multirow{3}{*}{$\begin{array}{l}\text { HBV, } \\
\text { HIV }\end{array}$} & \multirow[t]{3}{*}{ No } & \multirow[t]{3}{*}{ NR } & Scr. uptake: NR & \multirow[t]{3}{*}{$N R$} & \multirow{2}{*}{$\begin{array}{l}\text { Counseling sessions were } \\
\text { offered to provide education } \\
\text { to prevent infection } \\
\text { transmission, and HCV infected } \\
\text { couples are encouraged } \\
\text { to avoid marriage. No results } \\
\text { on medical follow-up reported. }\end{array}$} \\
\hline & & & & & & & & & \multirow[t]{2}{*}{$\begin{array}{l}\text { Prevalence: } \\
0.3 \%(250 / \\
74662 ; 95 \% \\
\text { Cl: } 0.3-0.4)^{* *}\end{array}$} & & \\
\hline & & & & & & & & & & & $\begin{array}{l}\text { Outcomes: } \\
\text { RNA rate: NR } \\
\text { Start treatment: NR } \\
\text { SVR: NR }\end{array}$ \\
\hline $\begin{array}{l}\text { Dubois, F, } \\
1994 \text { [94] }\end{array}$ & $N R$ & $\begin{array}{l}\text { Healthy subject } \\
\text { of routine } \\
\text { medical check } \\
\text { up }\end{array}$ & $\begin{array}{l}\text { France (1.1\%): } \\
\text { Western part }\end{array}$ & $\begin{array}{l}\text { Routine } \\
\text { medical } \\
\text { check up }\end{array}$ & 5 weeks & $\begin{array}{l}\text { ALT, } \\
\text { HAV, } \\
\text { HBV, } \\
\text { HDV }\end{array}$ & $\begin{array}{l}\text { Yes: elevated } \\
\text { ALT levels (vs } \\
\text { control group } \\
\text { without } \\
\text { elevated ALT) }\end{array}$ & $N R$ & $\begin{array}{l}\text { Scr. uptake: NR } \\
\text { Prevalence: } \\
4.9 \%(15 / \\
308 ; 95 \% \\
\text { Cl: } 3.0-7.9)^{* * *} \\
\\
\text { Control } \\
\text { group: } \\
0.3 \%(1 / 308)\end{array}$ & $\begin{array}{l}\text { Most } \\
\text { common risk } \\
\text { factors: } \\
\text { - Blood } \\
\text { transfusion } \\
\text { - History of } \\
\text { IDU }\end{array}$ & $\begin{array}{l}\text { Patients were referred to their } \\
\text { family physician (no results } \\
\text { reported). } \\
\text { Outcomes: } \\
\text { RNA rate: } 73.3 \%(11 / 15) \\
\text { RNA rate control gr: } 0 \%(0 / 1) \\
\text { Start treatment: NR } \\
\text { SVR: NR }\end{array}$ \\
\hline \multirow{2}{*}{$\begin{array}{l}\text { Roberts, J, } \\
2010[95] \\
\text { (abstract) }\end{array}$} & \multirow[t]{2}{*}{2009} & \multirow{2}{*}{$\begin{array}{l}\text { MSM attending } \\
\text { service and } \\
\text { who were } \\
\text { tested for HIV }\end{array}$} & \multirow[t]{2}{*}{$\begin{array}{l}\text { UK (1.1\%): } \\
\text { Brighton }\end{array}$} & \multirow{2}{*}{$\begin{array}{l}\text { Local outreach } \\
\text { services for HIV } \\
\text { point of care } \\
\text { testing }\end{array}$} & \multirow[t]{2}{*}{4 months } & \multirow{2}{*}{$\begin{array}{l}\text { HAV, } \\
\text { HBV, } \\
\text { syphilis, } \\
\text { HIV }\end{array}$} & \multirow{2}{*}{ No } & \multirow[t]{2}{*}{ NR } & $\begin{array}{l}\text { Scr. uptake: } \\
66.2 \%(55 / 82)\end{array}$ & \multirow[t]{2}{*}{ NR } & \multirow{2}{*}{$\begin{array}{l}\text { Subsequent attendance at STI } \\
\text { services remained low. } \\
\text { Follow-up of the HCV- } \\
\text { infected person was not } \\
\text { reported in detail. } \\
\text { Outcomes: } \\
\text { RNA rate: - } \\
\text { Start treatment: NR SVR: NR }\end{array}$} \\
\hline & & & & & & & & & $\begin{array}{l}\text { Prevalence: } \\
\text { 1.8\% CHCV } \\
(1 / 55 ; 95 \% \\
\text { Cl: } 0.1-9.6)^{* * * *}\end{array}$ & & \\
\hline
\end{tabular}


Table 7 Integrated screening programs integrated in other clinics or services (Continued)

\begin{tabular}{|c|c|c|c|c|c|c|c|c|c|c|c|}
\hline $\begin{array}{l}\text { Cohen, DE, } \\
2006 \text { [96] }\end{array}$ & 2001 & MSM & $\begin{array}{l}\text { USA (1.9\%): } \\
\text { Greater Boston } \\
\text { area }\end{array}$ & $\begin{array}{l}\text { Community care } \\
\text { facility }\end{array}$ & 8 months & None & No & Yes & $\begin{array}{l}\text { Scr. uptake: } \\
\text { NR } \\
\text { Prevalence: } \\
11.5 \%(25 / \\
218 ; 95 \% \mathrm{Cl} \text { : } \\
7.9-16.4)^{* * *}\end{array}$ & $\begin{array}{l}\text { Univariate } \\
\text { regr. analysis: } \\
\text { - HIV } \\
\text { infection } \\
\text { - HBV } \\
\text { infection } \\
\text { - Less } \\
\text { receptive } \\
\text { anal sex } \\
\text { - Lifetime } \\
\text { history of } \\
\text { gonorrhoea } \\
\text { - History of } \\
\text { IDU } \\
\text { - Reporting } \\
\text { blood on } \\
\text { shared } \\
\text { cocaine } \\
\text { straws } \\
\text { - Crack } \\
\text { cocaine use } \\
\text { in prior } 6 \\
\text { months }\end{array}$ & $\begin{array}{l}\text { Patients were referred to their } \\
\text { primary care provider (no } \\
\text { results reported). } \\
\text { Outcomes: } \\
\text { RNA rate: NR } \\
\text { Start treatment: NR } \\
\text { SVR: NR }\end{array}$ \\
\hline $\begin{array}{l}\text { Campello, C, } \\
2002 \text { [97] }\end{array}$ & 1994-1995 & $\begin{array}{l}\text { Individuals ages } \\
17-67 \text { years, } \\
\text { currently } \\
\text { employed in } \\
\text { the processing } \\
\text { and/or trade of } \\
\text { food and } \\
\text { beverages }\end{array}$ & $\begin{array}{l}\text { Italy }(1.1 \%) \text { : } \\
\text { Lombardia } \\
\text { region, } \\
\text { administrative } \\
\text { boundary of the } \\
\text { former USL } 22 \\
\text { (local health } \\
\text { unit) }\end{array}$ & $\begin{array}{l}\text { Periodic compulsory } \\
\text { health check for the } \\
\text { surveillance and } \\
\text { control of diseases } \\
\text { transmitted by the } \\
\text { fecal-oral route as } \\
\text { well as tuberculosis }\end{array}$ & 14 months & None & No & NR & $\begin{array}{l}\text { Scr. uptake: } \\
77.6 \%(2154 / \\
2776) \\
\\
\text { Prevalence: } \\
3.3 \%(71 / \\
2154 ; 95 \% \mathrm{Cl} \\
2.6-4.1)^{* * *}\end{array}$ & $\begin{array}{l}\text { Multivariable } \\
\text { regr. analysis: } \\
\text { - Age } \\
>50 \text { years } \\
\text { - Blood } \\
\text { transfusion } \\
- \text { History of } \\
\text { IDU } \\
- \text { Tattooing } \\
-<8 \text { years of } \\
\text { education } \\
\text { - Female sex }\end{array}$ & $\begin{array}{l}\text { Patients offered the } \\
\text { possibility of undergoing a } \\
\text { follow-up for the clinical and } \\
\text { laboratory evaluation of he- } \\
\text { patic involvement (no results } \\
\text { reported). } \\
\text { Outcomes: } \\
\text { RNA rate: } 71.8 \% \text { (51/71) } \\
\text { Start treatment: NR } \\
\text { SVR: NR }\end{array}$ \\
\hline \multirow[t]{2}{*}{$\begin{array}{l}\text { Tafuri, S, } \\
2010 \text { [98] }\end{array}$} & \multirow[t]{2}{*}{2008} & \multirow{2}{*}{$\begin{array}{l}\text { Asylum seekers } \\
\text { without signs } \\
\text { or symptoms in } \\
\text { recent or } \\
\text { remote past }\end{array}$} & \multirow[t]{2}{*}{ Italy (1.1\%): Bari } & \multirow[t]{2}{*}{$\begin{array}{l}\text { Asylum seeker } \\
\text { center }\end{array}$} & \multirow[t]{2}{*}{3 months } & \multirow[t]{2}{*}{$\begin{array}{l}\text { HBV, } \\
\text { HIV, } \\
\text { syphilis }\end{array}$} & \multirow[t]{2}{*}{ No } & NR & $\begin{array}{l}\text { Scr. uptake: } \\
71.1 \%(529 / \\
744)\end{array}$ & \multirow[t]{2}{*}{ NR } & $\begin{array}{l}\text { All patients who tested } \\
\text { positive were treated (no } \\
\text { results were reported). }\end{array}$ \\
\hline & & & & & & & & & $\begin{array}{l}\text { Prevalence: } \\
4.5 \% \text { (24/529; } \\
95 \% \text { Cl: } 3.06- \\
6.07)^{*}\end{array}$ & & $\begin{array}{l}\text { Outcomes: } \\
\text { RNA rate: NR } \\
\text { Start treatment: NR } \\
\text { SVR: NR }\end{array}$ \\
\hline
\end{tabular}

Note: $\mathrm{Cl}=$ confidence interval; $\mathrm{NR}=$ not reported; IDU = injecting drug use; $\mathrm{HCV}=$ hepatitis $\mathrm{C}$ virus; $\mathrm{CHCV}=$ chronic hepatitis $\mathrm{C}$ virus; $\mathrm{HBV}=$ hepatitis $\mathrm{B}$ virus; $\mathrm{HAV}=$ hepatitis $\mathrm{A}$ virus; $\mathrm{HDV}=$ hepatitis delta virus;

$H I V=$ human immunodeficiency virus; $A L T=$ alanine aminotransferase; $M S M=$ men who have sex with men; $S V R=$ sustained virological response; $P C R=$ polymerase chain reaction.

*HCV-antibody prevalence is considered suboptimal (data were collected before 1994 when sensitivity/specificity of tests was not optimal, or reactive HCV-antibody test results were not confirmed by immunoblot).

**The reliability of the reported HCV-antibody prevalence is undecided (data were collected after 1993, but the diagnostic tests are unspecified, or other than described below, or dried blood spots or oral fluid samples were used).

***HCV-antibody prevalence is considered valid; data were collected after 1993, and reactive HCV-antibody test results were confirmed by second or higher generation immunoblot assays from Ortho, Chiron, Novartis

(RIBA), Innogenetics (LiaTek), Pasteur (DECISCAN HCV), Genelabs Diagnostics (HCV BLOT), or Mikrogen (recomBlot HCV IgG 2.0).

****HCV-antibody prevalence is considered valid, but reflecting chronic HCV infection (data were collected after 1993, and reactive HCV antibody test results were confirmed by PCR) 


\section{General practitioners' clinics $(n=12)$ Program characteristics}

The majority (8/12) of the HCV-screening programs in GP clinics were carried out in France (see Table 3). In most programs (9/12), screening was limited to HCV risk groups within the GP-patient population (specific migrant groups [46,47]; risk groups such as those with a history of IDU and recipients of blood transfusions before 1991 $[70,72,73,75-78])$. One program was carried out in a health care center that attracted people with poor access to health care, mostly migrants [44], and one was carried out in an area of low socioeconomic status [71]. In two of the 12 programs, individuals who were in the GP's waiting room were approached and invited for screening $[44,46]$, and five programs used media activities to attract individuals for screening. Of the 12 studies, four reported that screening was free of cost $[70,73,78,99]$, whereas the others did not report participants' costs for screening. Only the screening program among people with poor access to health care offered the possibility of anonymous screening [44].

In reference to screening procedures, all but two studies used venipuncture for specimen collection. Two screening programs used oral fluid HCV antibody tests, followed by blood tests for those who tested positive. The majority (9/12) of the programs focused solely on HCV screening. The three programs that screened predominantly migrants also included HBV screening $[44,46,47]$.

\section{Program outcomes}

The number of individuals screened for HCV antibodies per program ranged from 117 to 15,952 . Six of the 12 programs reported the screening uptake, which varied from $27.8 \%$ to $82.5 \%$. The HCV prevalence varied from $0 \%$ to $30.8 \%$. Of the 12 programs, three primarily screened migrants (prevalences $0 \%, 1.2 \%$ and $5.8 \%$ ), seven used risk factors other than being a migrant as criteria for screening (prevalences $1.4 \%$ to $30.8 \%$ ), and one was performed in an area of low socioeconomic status (prevalence 12.8\%). In contrast, one program that did not use risk factors as screening criteria, and was not performed in an area of low socioeconomic status, found a relatively low prevalence of $0.4 \%$ [74]. We did not notice clear differences in screening uptake or $\mathrm{HCV}$ prevalence related to the use of media to attract individuals for screening. Further, we could not assess whether personally inviting individuals for screening or screening for more than just HCV could have influenced the screening uptake, since these studies did not report the screening uptake.

Four studies checked the results of their screening program against data collected in the same period in comparison clinics or data collected prior to the screening program. A study from the Netherlands concluded that the addition of primary care practice support leads to considerable improvements in medical awareness regarding $\mathrm{HCV}$ infection in primary care, which is likely to have a positive effect on case finding (that effect, however, could not be indisputably demonstrated) [76]. A study from France concluded that information and training that is adapted to GPs' medical practice can lead to more active involvement of GPs in screening for HCV infection [77]. During the intervention the number of GPs that prescribed $\mathrm{HCV}$ screening increased, and more $\mathrm{HCV}$-infected patients were detected compared with the year before. Another study from France compared two interventions in the GP clinic; GPs in intervention 1 prescribed HCV screening if $\mathrm{HCV}$ risk factors were identified during questioning of patients, whereas GPs in intervention 2 placed posters and leaflets on $\mathrm{HCV}$ risk factors in their waiting rooms to motivate patients at risk to discuss screening [78]. The numbers of tests prescribed by GPs was relatively low in both interventions, and outcomes of the two interventions with regard to the number of tests and the HCV prevalence were comparable. In a study from Scotland, HCV screening was offered to all GP visitors aged 3054 years and 117 individuals were screened (prevalence: $12.8 \%, 15 / 117)$, whereas in a comparison clinic, where no intervention for $\mathrm{HCV}$ screening was introduced, no individuals were screened for HCV [71]. Two of these programs reported the proportion who started treatment (18\% and $38 \%$ ), but only one of these two programs reported the proportion of treated individuals $(\mathrm{n}=2)$ who reached SVR $(50 \%, \mathrm{n}=1)[71]$.

\section{Veterans affairs clinics $(n=5)$ Program characteristics}

Table 4 presents the five HCV screening programs in VA clinics in the USA. No personal invitations or media activities were reported. All screening programs limited the screening to risk groups within the veteran population. In one program, screening was limited to veterans who were admitted for an alcohol and noninjecting drug rehabilitation program [82], while other programs used an extensive list of risk factors, including history of drug use, blood transfusion prior to 1992, and Vietnam veteran. None of the programs reported whether or not individuals could participate anonymously, participants' costs for screening, or a comparison group for evaluation purposes. All programs used venipuncture for specimen collection and screened solely for $\mathrm{HCV}$.

\section{Program outcomes}

The number of individuals screened for HCV antibodies per program ranged from 338 to 12,485. The screening uptake was described in three of the five programs, varying from $41.9 \%$ to $99.4 \%$. The HCV prevalence in most programs was around $5 \%$, but the program among veterans who were admitted to an alcohol and noninjecting 
drug rehabilitation program was substantially higher (23.1\%). The proportion of patients that started treatment was described in three studies and varied from $15 \%$ to $38 \%$. Four studies reported the SVR rate among those who started treatment, ranging from $33 \%$ to $47 \%$.

\section{Antenatal/obstetric/fertility clinics $(n=5)$ Program characteristics}

Of the five programs, three were carried out in the UK, one in the USA and one in Brazil (see Table 5). The programs targeted pregnant women, except for a British study in a fertility clinic that was targeted at couples. Media activities to promote the screening programs were described in only one of the five studies; this study used information leaflets to inform women about the screening program, and a personal invitation for participation by the midwife [87]. None of the programs used a risk assessment strategy to limit screening to those at risk. The programs did not report the possibility to screen anonymously, or a comparison group for evaluation purposes. The one program reporting screening costs was free of cost to participants [88].

With respect to screening procedures, all but one study used venipuncture for specimen collection. One study used DBS for anti-HCV screening and a second generation ELISA followed by HCV RNA testing using venous blood for confirmation [88]. In all but one program, participants were also screened for other infections (mainly HIV and HBV) or elevated liver enzymes (ALT/AST).

\section{Program outcomes}

The number of individuals screened for $\mathrm{HCV}$ antibodies per program ranged from 1,658 to 31,081 . In the two studies reporting screening uptake, rates were very high $(\geq 98 \%)$. In all but one program, the $\mathrm{HCV}$ prevalences were low, varying from $0.2 \%$ to $0.8 \%$. In women at risk for perinatal complications, $\mathrm{HCV}$ prevalence was $4.6 \%$ [86]. In one of the five programs, results of the clinical follow-up and treatment were reported, showing that $67.9 \%$ of those identified with chronic HCV started treatment after delivery, and $80 \%$ of those who completed treatment achieved SVR [84].

\section{Psychiatric clinics $(\mathrm{n}=3)$ Program characteristics}

Of the three $\mathrm{HCV}$ screening programs in psychiatric clinics, two were carried out in Australia, and one in the USA (see Table 6). One program aimed to evaluate whether screening by risk factors would be effective, and limited the HCV screening program in one unit to those with a history of IDU and those exposed to contaminated blood products, whereas in the other unit all patients were screened [90]. In the other two programs, no risk selection was used for participation in the screening program. One program promoted screening by using media [91]. The programs did not offer the possibility to screen anonymously, and did not report about participants' costs for screening. Concerning screening procedures, all studies used venipuncture for specimen collection, and all studies exclusively screened for HCV.

\section{Program outcomes}

The number of individuals screened for $\mathrm{HCV}$ antibodies per program ranged from 36 to 98 . All programs reported the screening uptake, varying from $20.5 \%$ to $100 \%$. The HCV prevalences varied from $3.2 \%$ in the unit without pre-screening risk selection [90], to $41.7 \%$ in the unit where screening was limited to those who reported a history of IDU or exposure to contaminated blood products. Noninjecting drug use and history of IDU were reported as the main risk factors among the identified cases. All three programs referred the $\mathrm{HCV}$ infected individuals to a specialist. Of interest, in two programs $[90,91]$, post-test counseling addressing various topics (e.g., education about the illness, risk behavior, safe injection practices, secondary prevention) was also offered to those who reported risk factors but tested $\mathrm{HCV}$ negative.

One of the three studies reported that their program was based on psychosocial theory or knowledge about determinants facilitating participation in HCV screening programs. This program promoted screening by using leaflets outlining $\mathrm{HCV}$, its risk factors, and the importance of screening, and used individually tailored preand post-test counseling that was adapted to individual knowledge and cultural understandings where appropriate [91]. Although the uptake of screening in that study was relatively low (20.5\%), the prevalence was relatively high (19.7\%), especially considering the fact that no prescreening risk selection was used.

\section{Other clinics $(n=7)$ \\ Program characteristics}

In total, seven HCV screening programs were integrated in other clinics or services (see Table 7). These programs varied widely, from screening patients at an emergency health unit in France [92] to screening couples that wish to get married in Saudi Arabia [93]. Two programs targeted MSM; one in an outreach service for HIV pointof-care testing in the UK [95], and another in a community care facility in the USA [96].

The study in the USA reported the use of media activities to attract participants, wherein MSM were recruited through advertisements as well as by referral of medical staff [96]. Two of the seven studies used a prescreening selection; a program at an emergency health unit only screened those with a reported risk factor [92], and in 
France, only those with elevated ALT levels as determined during routine medical check-up were screened for $\mathrm{HCV}$ [94]. None of the programs reported about the possibility of anonymous screening, or a comparison group for evaluation purposes. The one study reporting about participants' costs for screening mentioned that it was free [96]. With respect to screening procedures, all studies used venipuncture for specimen collection. Four of the seven programs also screened for other diseases (mainly HBV).

\section{Program outcomes}

The number of individuals screened for HCV antibodies per program ranged from 55 to 74,662 . The screening uptake was reported in three out of seven programs, varying from $66.2 \%$ to $77.6 \%$. The $\mathrm{HCV}$ prevalence varied from $0.3 \%$ in a mandatory premarital screening program in Saudi Arabia [93] to $11.5 \%$ in a program for MSM [96]. Only one study reported the number of patients that started treatment, which was zero [92].

\section{Discussion}

This systematic review describes characteristics and outcomes of $\mathrm{HCV}$ screening programs in the general population, and includes 67 programs. In total, 24 of them were exclusively set up for the purpose of $\mathrm{HCV}$ screening, whereas 41 were integrated in already existing health care facilities (not aimed at $\mathrm{HCV}$ risk groups), and two programs used both an integrated and nonintegrated approach. Altogether, the programs that were published identified approximately 25,700 HCVinfected individuals. Clearly, large-scale, and long-term screening and referral programs are needed to address the HCV-related burden of disease in an era of potent therapy for HCV.

The programs were highly heterogenic in their organization, recruitment, and screening procedure, and the vast majority did not use a comparison group to assess the effectiveness of their screening program. Hence, we cannot draw firm conclusions as to which screening program strategy, or which program characteristic (e.g., free-of-cost vs. low-cost screening, anonymous vs. nonanonymous screening, use of particular media to promote screening) is more effective than another in attracting or motivating individuals for screening or in attracting those at higher risk for HCV. Screening programs that compare different recruitment and screening strategies are needed to gain insight into effectiveness of strategies and program characteristics.

In addition, many studies did not report program characteristics (e.g., the laboratory tests that were used). The same was true for screening uptake and follow-up data regarding $\mathrm{HCV}$-related care, and even if reported, there was not much consistency (e.g., some reported the SVR rate among those who completed treatment, whereas others reported that treatment was 'rather successful'). The underreporting and the lack of uniformity of data reporting greatly hinder the comparison of screening programs. Data reporting standards (see Parameters of screening programs) are needed to be able to compare screening program characteristics and outcomes in order to find out which factors are effective. If demonstration projects for HCV screening are not able to demonstrate direct effects in terms of number of individuals who tested positive for $\mathrm{HCV}$ that are linked to care, secondary evaluation measures could be used. For instance by monitoring rates of HCV screening and positivity in the hospital or referral laboratory and by comparing these data with data from previous years or from hospitals or laboratories that were not involved in the demonstration project.

In general, we noticed relatively high $\mathrm{HCV}$ prevalences in programs that used a prescreening selection based on $\mathrm{HCV}$ risk factors (especially in programs that used elevated ALT or a history of IDU as indications for HCV screening) or migrant status, in programs that were carried out in intermediate to high $\mathrm{HCV}$-prevalence countries or regions, and in programs in psychiatric clinics. Also, relatively high $\mathrm{HCV}$ prevalences were found in nonintegrated programs in low HCV-prevalence countries that targeted the general population (see Additional file 1: Table S1, row 1-7), even without a prescreening risk assessment. These programs might have screened a self-referred population, and may have attracted those at risk of $\mathrm{HCV}$ in the general population, and therefore observed prevalences are higher than those in the general population. For the study by Hayashi etal (see Additional file 1: Table S1), screening was performed in a specific region in Japan with a presumably high HCV prevalence, explaining the very high prevalence that was found. In most studies, a history of IDU was the main risk factor among the identified HCV-infected individuals. In general, low $\mathrm{HCV}$ prevalences were found in programs that targeted health care workers, and in programs that were carried out in antenatal clinics. Programs in STD and GP clinics that did not use a prescreening risk selection also found relatively low HCV prevalences.

Only one study reported that the promotion of the screening program was based on theoretical insights or knowledge about determinants facilitating participation in screening programs. None of the studies reported the use of simple tools that may increase the screening uptake, such as reminder messages [100], or support with planning of when and how to get screened (i.e., creating implementation intentions [101]). In many studies, and especially those describing nonintegrated programs, the uptake of screening was not reported.

We found that integrated screening programs in general screened a larger number of individuals than did nonintegrated screening programs in low $\mathrm{HCV}$-prevalence 
countries. Integrated screening programs have three advantages in that they do not have to attract their target population for screening, and they can use a facility that is familiar to the public. In addition, they can facilitate continuous screening and follow-up of individuals at relatively low cost, whereas nonintegrated programs offer screening usually for a limited period. On the other hand, integrated screening programs only reach those who have a reason to visit such facilities (unless media campaigns have been used to attract more people), whereas nonintegrated programs may attract a different risk population that otherwise would not be screened and do not perceive themselves at risk for HCV (i.e., the hidden population). We believe that both approaches are useful and complementary. In addition, since nonintegrated screening in general is more complex to organize, it may be efficient to screen for other diseases simultaneously, when risk groups overlap.

We identified several studies that did not confirm HCV antibody test results. Many of the identified programs targeted asymptomatic individuals in the general population with a relatively low $\mathrm{HCV}$ prevalence. In such populations, unconfirmed HCV antibody test results may include 35\% (range: 15\%-60\%) false-positive test results [102]. Hence, the program outcomes that are reported may include a substantial degree of uncertainty, and should be interpreted with care. We like to emphasize that HCV screening programs should use validated screening methods, and describe the tests that were used when publishing the results of their screening programs.

As for study limitations, the majority of the screening programs that were evaluated in this review occurred in just a few countries (USA, UK, and France), most likely since this review was limited to studies published in English, French, German, Spanish, and Dutch. Therefore, the results may not be generalizable to other (non-Western) countries or countries with a higher HCV prevalence. With respect to publication bias, this review only includes screening programs that were published and programs that were successful in identifying HCVinfected individuals may have been more likely to be published. However, we did identify several programs in which no individuals were diagnosed. Furthermore, as identification of $\mathrm{HCV}$-infected individuals serves a clinical goal and not necessarily a scientific goal, not all screening efforts have been evaluated or published. Our search identified several announcements of HCV screening activities $[103,104]$ or cost-effectiveness evaluations of screening activities [105] that did not provide any further information about the screening program and/or outcomes. Further, our review describes several screening programs, but it cannot determine the efficiency and effectiveness of these screening programs in preventing future $\mathrm{HCV}$-related morbidity and mortality. Measuring these effects of $\mathrm{HCV}$ screening programs is a challenge because randomized, controlled trials or comparison groups and decades of follow-up time are required. As an alternative method, mathematical modelling studies can be useful to estimate long-term effects of screening programs (e.g., [106,107]), especially when certain program outcomes (e.g., participation rate, prevalence) are used as parameters in the model. The efficiency and effectiveness of screening also depends on the uptake and outcomes of therapy and other preventive measures that may follow from diagnosis. Efficiency relates to the number needed to be screened to identify a treatable case of HCV. Surprisingly, most studies did not report such data, and merely mentioned that HCVinfected individuals were notified of their test result and referred for clinical care. Following Wilson and Jungners third screening principle [108], facilities for diagnosis and treatment should be available. This means that the screening program itself is as important as the efforts that are undertaken to bring identified patients into care and have them benefit from preventive measures and/or treatment. Hence, evaluation reports of screening programs should include clinical follow-up and systematically report outcomes.

A recent systematic review by Jones etal on the effectiveness and cost-effectiveness of interventions aimed at raising awareness of and/or increasing engagement in case finding and screening with high-risk groups for $\mathrm{HCV}$ and HBV and practitioners included only programs with a comparison group (e.g., randomized controlled trials, preand postintervention data, repeated cross-sectional studies) [109]. About half of the studies $(12 / 25)$ included in that review were aimed at high-risk groups for HCV that are relatively easy to target, such as current IDU and incarcerated individuals, whereas our review includes studies that aimed to identify the hidden population of $\mathrm{HCV}$-infected individuals. Jones etal identified drug services and primary care as settings in which interventions could effectively increase screening uptake. They also found that DBS screening in addition to venipuncture might increase HCV screening uptake in drugs services or prisons. In our review, a few studies reported the use of home collection tests, DBS, or oral fluid tests, but these studies did not demonstrate high screening uptake. Further insight into the effect of alternative noninvasive screening procedures on screening uptake is needed. As in our review, Jones etal concluded that improvement of health outcomes following diagnosis for those identified with chronic HCV deserves careful attention.

In the United States it has recently been recommended that all people born between 1945 and 1965 should be offered a one-time screening without prior risk assessment [110], since HCV prevalence in this group is four times greater than adults aged 20 years or older who were born outside of the birth cohort, and identifying this group through a high risk profile has been unsuccessful so far. More importantly, this 
screening strategy is estimated to be cost-effective assuming an uptake of 15\% [106]. Although a relatively low uptake of $15 \%$ was assumed in the cost-effectiveness model in the USA, those who participate may not be representative for the total population of baby boomers. It may be that those at lower risk for $\mathrm{HCV}$ (i.e., the worried-well) could be more likely to respond. Thus, although it may be promising, the effectiveness of such an intervention needs to be demonstrated in practice. Nevertheless, it should be examined whether it is feasible and cost-effective to implement such a birth cohort screening in countries with a lower HCV prevalence.

\section{Conclusions}

$\mathrm{HCV}$ infection has serious health implications and, at the start of the era of potent therapy for $\mathrm{HCV}$, screening programs are not yet reaching all potentially infected individuals worldwide. Therefore more effective programs are urgently needed. This review identified 67 screening programs that targeted HCV risk groups that are hidden in the general population. Relatively high HCV prevalences were found in programs that used a prescreening selection based on a HCV risk profile or migrant status, in programs that were carried out in intermediate to high HCV-prevalence countries or regions, and in programs in psychiatric clinics. In general, low $\mathrm{HCV}$ prevalences were found in programs that targeted health care workers and pregnant women. The reported use of motivational communication based on theory and/or determinants facilitating screening, and tools to increase HCV screening uptake were virtually absent. Comparison of the screening programs was strongly hindered by the lack of reported data on screening uptake, program characteristics, the type of diagnostic tests used, and clinical outcomes. In addition, only a few programs used a comparison group to evaluate program effectiveness.

We suggest that for low HCV-prevalence populations, the use of prescreening selection criteria should be considered to increase efficiency. In addition, to be able to assess screening program effectiveness, programs using a comparison group are needed. To improve comparability of screening programs and outcomes, it is necessary for all programs to systematically report program characteristics, screening uptake, the type of diagnostic tests that were used, as well as clinical outcomes.

\section{Additional file}

Additional file 1: Table S1. Nonintegrated screening programs in low HCV-prevalence countries ( $\leq 2 \%)$ [23,46-54,111-123].

\section{Competing interests}

The authors declare that they have no competing interests.

\section{Authors' contributions}

FRZ and ATU designed and performed the literature review, collected data from individual studies, participated in data interpretation, and drafted the manuscript. CWH and CHSBB participated in the study selection process, UD contributed to the study design and drafting of the manuscript. MWL supervised the study, and led the writing. MP conceived and supervised the study, participated in the study selection process, and led the writing. All authors read and approved the final manuscript.

\section{Acknowledgements}

This study was conducted within the Sarphati Initiative: the Academic Collaborative Center on Public Health of Noord Holland and Flevoland, the Netherlands. The study was funded by the Netherlands Organization for Health Research and Development (ZonMw; grant numbers 505040598104, 71150001, and 61200016). The authors would like to thank Heleen Dysterinck and Arnold Leenders of the Medical Library of the Academic Medical Center, Amsterdam, for their help with defining the search strategy and the use of Reference Manager; Jan Vlierhuis and his colleagues of the library of the Public Health Service of Amsterdam for their help with retrieving the articles; Nienke Alberts of the Public Health Service of Amsterdam for screening the Spanish language articles; Roel Coutinho of the National Center for Public Health and the Environment, Bilthoven, the Netherlands, and Gerjo Kok of Maastricht University, the Netherlands for their contribution to the manuscript; Theo Cuypers of Sanquin Blood Supply, Amsterdam, the Netherlands, for advice on the reliability of HCV diagnostic tests; and Susan T. Landry for editing of the manuscript.

\section{Author details}

${ }^{1}$ Public Health Service of Amsterdam, the Netherlands, Infectious Diseases Cluster, P.O. Box 2200, Amsterdam 1000 CE, The Netherlands. ${ }^{2}$ Center for Infection and Immunology Amsterdam (CINIMA), Academic Medical Center (University of Amsterdam), P.O. Box 22660, Amsterdam 1100 DD, The Netherlands. ${ }^{3}$ Dutch Cochrane Centre, Academic Medical Center, P.O. Box 22660, Amsterdam 1100 DD, The Netherlands. ${ }^{4} J u l i u s$ Center for Health Sciences and Primary Care, University Medical Center Utrecht, P.O. Box 85500, Utrecht 3508 GA, The Netherlands.

Received: 2 September 2013 Accepted: 10 January 2014

Published: 22 January 2014

\section{References}

1. Lavanchy D: The global burden of hepatitis C. Liver Int 2009, 29(Suppl 1):74-81.

2. McHutchison JG: Understanding hepatitis C. Am J Manag Care 2004, 10:S21-S29.

3. Micallef JM, Kaldor JM, Dore GJ: Spontaneous viral clearance following acute hepatitis $C$ infection: a systematic review of longitudinal studies. J Viral Hepat 2006, 13:34-41.

4. Seeff LB: Natural history of chronic hepatitis C. Hepatology 2002, 36(5 Suppl 1):S35-S46.

5. Spradling PR, Rupp L, Moorman AC, Lu M, Teshale EH, Gordon SC, Nakasato C, Boscarino JA, Henkle EM, Nerenz DR, Denniston MM, Holmberg SD: Hepatitis $B$ and $C$ virus infection among 1.2 Million persons with access to care: factors associated with testing and infection prevalence. Clin Infect Dis 2012, 55:1047-1055.

6. Hagan H, Campbell J, Thiede H, Strathdee S, Ouellet L, Kapadia F, Hudson S, Garfein RS: Self-reported hepatitis C virus antibody status and risk behavior in young injectors. Public Health Rep 2006, 121:710-719.

7. Volk ML, Tocco R, Saini S, Lok AS: Public health impact of antiviral therapy for hepatitis C in the United States. Hepatology 2009, 50:1750-1755.

8. Grishchenko M, Grieve RD, Sweeting MJ, De Angelis D, Thomson BJ, Ryder SD, Irving WL: Cost-effectiveness of pegylated interferon and ribavirin for patients with chronic hepatitis $C$ treated in routine clinical practice. Int J Technol Assess Health Care 2009, 25:171-180.

9. Siebert U, Sroczynski G, Rossol S, Wasem J, Ravens-Sieberer U, Kurth BM, Manns MP, McHutchison JG, Wong JB: Cost effectiveness of peginterferon alpha- $2 \mathrm{~b}$ plus ribavirin versus interferon alpha- $2 \mathrm{~b}$ plus ribavirin for initial treatment of chronic hepatitis C. Gut 2003, 52:425-432.

10. Dore GJ, Matthews GV, Rockstroh J: Future of hepatitis C therapy: development of direct-acting antivirals. Curr Opin HIV AIDS 2011, 6:508-513. 
11. Ghany MG, Nelson DR, Strader DB, Thomas DL, Seeff LB: An update on treatment of genotype 1 chronic hepatitis $C$ virus infection: 2011 practice guideline by the American Association for the Study of Liver Diseases. Hepatology 2011, 54:1433-1444.

12. Friis $\mathrm{RH}$, Sellers TH: Screening for Disease in the Community. In Epidemiology for Public Health Practice. 4th edition. Canada: Jones and Bartlett Publishers, LLC; 2009:409-436.

13. Centers for Disease Control and Prevention: Recommendations for prevention and control of hepatitis $\mathrm{C}$ virus (HCV) infection and HCV-related chronic disease. MMWR 1998, 47(No. RR-19):20-26.

14. Mofenson LM, Brady MT, Danner SP, Dominguez KL, Hazra R, Handelsman E, Havens P, Nesheim S, Read JS, Serchuck L, Van Dyke R: Guidelines for the Prevention and Treatment of Opportunistic Infections among HIV-exposed and HIV-infected children. MMWR Recomm Rep 2009, 58:1-166.

15. Lucidarme D, Decoster A, Fremaux D, Harbonnier J, Jacob C, Vosgien V, Josse $P$, Villeger $P$, Henrio C, Prouvost-Keller B, Saccardy C, Lemaire M, Vazeille G, Duchene C, Thuillier M, Colbeaux C, Lefebvre AM, Forzy G, Filoche B: Routine practice HCV infection screening with saliva samples: multicentric study in an intravenous drug user population. Gastroenterol Clin Biol 2007, 31:480-484.

16. Makris M, Baglin T, Dusheiko G, Giangrande PL, Lee CA, Ludlam CA, Preston FE, Watson HG, Wilde JT, Winter M: Guidelines on the diagnosis, management and prevention of hepatitis in haemophilia. Haemophilia 2001, 7:339-345

17. Centers for Disease Control and Prevention: Guidelines for prevention and treatment of opportunistic infections in HIV-infected adults and adolescents. MMWR 2009, 58(No. RR-4):85-86 (No. RR-4).

18. Vriend $H J$, van Veen MG, Prins M, Urbanus AT, Boot HJ, Op de Coul ELM: Hepatitis $C$ virus prevalence in the Netherlands: migrants account for most infections. Epidemiol Infect 2013, 141(6):1310-1317.

19. Vrielink H, Reesink HW, van den Burg PJ, Zaaijer HL, Cuypers HT, Lelie PN van der Poel CL: Performance of three generations of anti-hepatitis $C$ virus enzyme-linked immunosorbent assays in donors and patients. Transfusion 1997, 37:845-849.

20. Glanz K, Bishop DB: The role of behavioral science theory in development and implementation of public health interventions. Annu Rev Public Health 2010, 31:399-418.

21. Alter HJ: New kit on the block: evaluation of second-generation assays for detection of antibody to the hepatitis C virus. Hepatology 1992, 15:350-353.

22. Gretch DR: Diagnostic tests for hepatitis C. Hepatology 1997, 26:43S-47S.

23. Shepard CW, Finelli L, Alter MJ: Global epidemiology of hepatitis C virus infection. Lancet Infect Dis 2005, 5:558-567.

24. Hao F: Prevalence of hepatitis $C$ virus infection in pregnant women. Zhonghua Fu Chan Ke Za Zhi 1993, 28:668-702.

25. Lu C: A seroepidemiological investigation on HCV infection among population in Tianjin area. Zhonghua Liu Xing Bing Xue Za Zhi 1993, 14:147-150

26. Fujimoto K, Momosaka Y, Uchida K, Ide H, Narisada H, Fujishiro K, Oda S, Okubo T: Implication of health checkups of students from developing countries in Japan. Nippon Koshu Eisei Zasshi 1999, 46:476-486.

27. Fukui M: Natural history of HCV seropositive cases found in health screening. Hokkaido lgaku Zasshi 1995, 70:69-82.

28. Imai Y, Tanaka H, Fukudai K, Zushi S, Yabuta T, Tujino A, Kurokawa M, Kono Y, Nishi K, Hayashi M: Present status of community-based HCV screening in Ikeda-Toyono Region, Osaka Prefecture, 2002. Acta Hepatologica Japonica 2004, 45:232-238.

29. Ishizuka M: Economic evaluation of health care program for hepatitis C virus antibody screening. Nippon Koshu Eisei Zasshi 1999, 46:447-465.

30. Kajikawa T, Katahira Y, Ohto M, Hara K, Umezono T, Saito M, Yoshikawa M, Sugiura N, Ebara M, Saisho H: Epidemiologic aspects of cases with positive HCV antibody and clinical features of hepatocellular carcinoma with positive HCV antibody based on mass survey in a rural area of Chiba prefecture. Acta Hepatologica Japonica 1996, 37:13-18.

31. Kuroki T, Murai J, Fujino K, Ozaki S, Nakagishi M, Toukaiya M: The screening of hepatitis virus and its efficacy. Rinsho Byori 1995, 43:1095-1100.

32. Michitaka K, Horiike N, Ohta Y: An epidemiological study of hepatitis C virus infection in a local district in Japan. Rinsho Byori 1991, 39:586-591.

33. Watanabe Y, Machida K, Sato A, Ota S, Kiyosawa K: Survey for hepatitis in an isolated endemic area. Nippon Koshu Eisei Zasshi 1996, 43:989-996.
34. Jonsdottir $\mathrm{G}$, Briem H, Blondal T, Palsson G, Olafsson S, Gudnason T: Viral hepatitis B and C among immigrants in Iceland. Laeknabladid 2006, 92:669-673.

35. Djeneva $\mathrm{H}$, Aleksieva T: Screening of hepatitis markers for viral hepatitis B and C in healthy persons in the region of Stara Zagora. Bulg Med 2003, 11:6-8.

36. Galetskii SA, Seniuta NB, Syrtsev AV, Abdullaev OM, Aliev DA, Kerimov AA, Yamashita M, Hayami M, Kato T, Mizokami M: Analysis of some viral infections, transmitted by parenteral and sexual routes, in the Republic of Azerbaijan. Vopr Virusol 1999, 44:232-236.

37. Netesova IG, laroslavtseva OA, Dryga SA, Posukh OL, Osipova LP, Bronshtein EL, Zaitsev SA, Netesov SV: Frequency of encountering markers of viral hepatitis $A, B$, and $C$ in the aboriginal inhabitants of the northwest region of Siberia. Vopr Virusol 1995, 40:172-174.

38. Tagizadeh RK, Mammadov MK, Dadashova AE, Azimova AA: Infections caused by hepatitis virus $B$ and $C$ at inhabitants of Baku. Azerbaijan Med J 2008, 1:131-134.

39. Ayvaz A, Nur N, Engin A, Cetinkaya S: Prevalence of hepatitis B and C in first grade primary school children living in Sivas, Turkey. Turk Pediatri Arsivi 2010, 45:132-136.

40. Cagatay M, Tulek N, Koksalan H, Mert A: Prevalence of hepatitis C virus antibodies in hospital personnel. Mikrobiyol Bul 1992, 26:242-247.

41. Pazdiora P, Topolcan O, Herynkova R: Hepatitis C antibodies in health personnel. Cesk Epidemiol Mikrobiol Imunol 1994, 43:29-31.

42. Chen CJ, Lu SN, You SL, Wu MH, Wang LY, Lee LT, Huang GT, Yang PM, Lee HS: Community-based hepatocellular carcinoma screening in seven townships in Taiwan. J Formos Med Assoc 1995, 94(Suppl 2):S94-102.

43. Tung W-C, Lu S-N, Wu M-H, Chen C-J: Screening of chronic active hepatitis from series of health examination database. J Intern Med Taiwan 2004, 15:65-75.

44. Pauti MD, Simonnot N, Estecahandy P: Development of prevention programmes for HIV, hepatitis and sexually transmitted infections among migrants consulting in the doctors of the World French centers. Med Mal Infect 2008, 38:495-499.

45. Pauti MD, Simonnot N, Estecahandy P: Development of actions for the prevention of HIV, hepatitis and Sexually Transmitted Infections among immigrants consulting in the Doctors of the World "Missions France". Med Mal Infect 2009, 39:191-195.

46. Uddin G, Shoeb D, Solaiman S, Marley R, Gore C, Ramsay M, Harris R, Ushiro-Lumb I, Moreea S, Alam S, Thomas HC, Khan S, Watt B, Pugh RN, Ramaiah S, Jervis R, Hughes A, Singhal S, Cameron S, Carman WF, Foster GR: Prevalence of chronic viral hepatitis in people of south Asian ethnicity living in England: the prevalence cannot necessarily be predicted from the prevalence in the country of origin. J Viral Hepat 2010, 17:327-335.

47. Kallman JB, Tran S, Arsalla A, Haddad D, Stepanova M, Fang Y, Wrobel VJ, Srishord M, Younossi ZM: Vietnamese community screening for hepatitis B virus and hepatitis C virus. J Viral Hepat 2011, 18(1):70-76.

48. Boyce $D E$, Tice $A D$, Ona FV, Akinaka KT, Lusk H: Viral hepatitis in a homeless shelter in Hawai'i. Hawaii Med J 2009, 68:113-115.

49. Datta SD, Armstrong GL, Roome AJ, Alter MJ: Blood exposures and hepatitis $C$ virus infections among emergency responders. Arch Intern Med 2003, 163:2605-2610.

50. Hwang JP, Mohseni M, Gor BJ, Wen S, Guerrero H, Vierling JM: Hepatitis B and hepatitis $C$ prevalence and treatment referral among Asian Americans undergoing community-based hepatitis screening. Am J Public Health 2010, 100(Suppl 1):S118-S124.

51. Jimenez FP, Fuentes HM, Borbolla BE: Anti-HCV in patients transfused, in a health area attended by a family physician. Medical Office 19 de Abril. Acta Gastroenterol Latinoam 2000, 30:99-105.

52. D'Souza RF, Glynn MJ, Alstead E, Foster GR, Ushiro-Lumb I: Improving hepatitis $C$ services across the UK: response to a walk-in HCV testing service. Gut 2004, 53:1388.

53. Trepka MJ, Zhang G, Leguen F, Obiaja K, Malow RM, De La Rosa M: Benefits and adverse effects of hepatitis $C$ screening: early results of a screening program. J Public Health Manag Pract 2007, 13:263-269.

54. Plard C, Shelly M, Millot J, Segouin C, Bertrand D, Le Divenah A: Anonymous and free screenings: population comparison between those conducted on-site in a testing centre and those done off-site. Sante Publique 2007, 19:355-362.

55. Meky FA, Stoszek SK, Abdel-Hamid M, Selim S, Abdel-Wahab A, Mikhail N, El-Kafrawy S, El-Daly M, Abdel-Aziz F, Sharaf S, Mohamed MK, Engle RE, Emerson SU, Purcell RH, Fix AD, Strickland GT: Active surveillance for acute viral hepatitis in rural villages in the Nile Delta. Clin Infect Dis 2006, 42:628-633. 
56. Lu SN, Chen HC, Tang CM, Wu MH, Yu ML, Chuang WL, Lu CF, Chang WY, Chen CJ: Prevalence and manifestations of hepatitis $C$ seropositivity in children in an endemic area. Pediatr Infect Dis J 1998, 17:142-145.

57. Aslam M, Aslam J: Seroprevalence of the antibody to hepatitis $C$ in select groups in the Punjab region of Pakistan. J Clin Gastroenterol 2001, 33:407-411.

58. Chen $\mathrm{CH}$, Yang PM, Huang GT, Lee HS, Sung JL, Sheu JC: Estimation of seroprevalence of hepatitis $B$ virus and hepatitis $C$ virus in Taiwan from a large-scale survey of free hepatitis screening participants. J Formos Med Assoc 2007, 106:148-155.

59. D'Souza G, Arafat R, Hwang L, Cunningham C, Shah S, Reynolds K: Cross-sectional survey of the extent and indicators of hepatitis $C$ virus infection in Houston Department of Health and Human Services' sexually transmitted disease clinics. J Viral Hepat 2003, 10:134-140.

60. Scott C, Day S, Low E, Sullivan A, Atkins M, Asboe D: Unselected hepatitis C screening of men who have sex with men attending sexual health clinics. J Infect 2010, 60:351-353.

61. Weisbord JS, Trepka MJ, Zhang G, Smith IP, Brewer T: Prevalence of and risk factors for hepatitis $C$ virus infection among STD clinic clientele in Miami, Florida. Sex Transm Infect 2003, 79:E1.

62. Gunn RA, Murray PJ, Brennan CH, Callahan DB, Alter MJ, Margolis HS: Evaluation of screening criteria to identify persons with hepatitis $C$ virus infection among sexually transmitted disease clinic clients: results from the San Diego Viral Hepatitis Integration Project. Sex Transm Dis 2003, 30:340-344

63. Mapagu MC, Martin SJ, Currie MJ, Bowden FJ: Screening for hepatitis C in sexual health clinic attendees. Sex Health 2008, 5:73-76.

64. Zimmerman R, Finley C, Rabins C, McMahon K: Integrating viral hepatitis prevention into STD clinics in Illinois (excluding Chicago), 1999-2005. Public Health Rep 2007, 122(Suppl 2):18-23.

65. Subiadur J, Harris JL, Rietmeijer CA: Integrating viral hepatitis prevention services into an urban STD clinic: Denver, Colorado. Public Health Rep 2007, 122(Suppl 2):12-17.

66. Heseltine G, McFarlane J: Texas statewide hepatitis $C$ counseling and testing, 2000-2005. Public Health Rep 2007, 122(Suppl 2):6-11.

67. Gunn RA, Murray PJ, Ackers ML, Hardison WG, Margolis HS: Screening for chronic hepatitis $B$ and $C$ virus infections in an urban sexually transmitted disease clinic: rationale for integrating services. Sex Transm Dis 2001, 28:166-170.

68. Ellks R: Hepatitis $C$ testing should be performed routinely in all patients attending sexual health services. Abstract for the 2nd Joint Conference of the British HIV Association and the British Association for Sexual Health and HIV Manchester United Kingdom. HIV Med 2010, 59.

69. Tweed E, Brant L, Hurrelle M, Klapper P, Ramsay M: Hepatitis C testing in sexual health services in England, 2002-7: results from sentinel surveillance. Sex Transm Infect 2010, 86:126-130.

70. Monnet E, Mercet P, Woronoff-Lemsi MC, Bresson-Hadni S, Pruniaux J, Cottray P, Bouiller C, Allemand H, Miguet JP: Organized hepatitis C screening. Results and cost of a one-year campaign in a pilot area. Gastroenterol Clin Biol 2000, 24:541-546.

71. Anderson EM, Mandeville RP, Hutchinson SJ, Cameron SO, Mills PR, Fox R, Ahmed S, Taylor A, Spence E, Goldberg DJ: Evaluation of a general practice based hepatitis $C$ virus screening intervention. Scott Med J 2009, 54:3-7.

72. Ouzan D, Cavailler P, Hofliger P, Mamino C, Joly H, Tran A: Modalities of care in anti HCV positive patients identified in General Medicine in the Alpes-Maritimes district. Gastroenterol Clin Biol 2003, 27:376-380.

73. Josset V, Torre JP, Tavolacci MP, Van Rossem-Magnani V, Anselme K, Merle V, Godart J, Libert A, Ladner J, Czernichow P: Efficiency of hepatitis C virus screening strategies in general practice. Gastroenterol Clin Biol 2004, 28:351-357.

74. Pradat P, Caillat-Vallet E, Sahajian F, Bailly F, Excler G, Sepetjan M, Trepo C, Fabry J: Prevalence of hepatitis $C$ infection among general practice patients in the Lyon area, France. Eur J Epidemiol 2001, 17:47-51.

75. Altman C, Lesiour A, Dunbavand A, Meyer L, de la Selle P, Buffet C: Screening of patients at risk for hepatitis $C$ virus infection in general medicine. Gastroenterol Clin Biol 1999, 23:359-362.

76. Helsper CW, van Essen GA, Bonten MJ, de Wit NJ: A support programme for primary care leads to substantial improvements in the effectiveness of a public hepatitis C campaign. Fam Pract 2010, 27:328-332.

77. Sahajian F, Excler G, Bailly F, Caillat-Vallet E, Trepo C, Sepetjan M, Fabry JY: Hepatitis $C$ screening practices among private practitioners: impact of an information campaign. Gastroenterol Clin Biol 2004, 28:714-719.
78. Roudot-Thoraval F, Monnet E, Mercet P, Bastie A, Dhumeaux D, Miguet JP: Strategies of hepatitis $C$ screening in general practice. Results of a twocenter randomized trial. Gastroenterol Clin Biol 2000, 24:1037-1041.

79. Groom H, Dieperink E, Nelson DB, Garrard J, Johnson JR, Ewing SL, Stockley $H$, Durfee J, Jonk Y, Willenbring ML, Ho SB: Outcomes of a Hepatitis C screening program at a large urban VA medical center. $J$ Clin Gastroenterol 2008, 42:97-106.

80. Mallette $C$, Flynn MA, Promrat $\mathrm{K}$ : Outcome of screening for hepatitis $\mathrm{C}$ virus infection based on risk factors. Am J Gastroenterol 2008, 103:131-137.

81. Cheung RC, Cunningham BA, Cooper AD: Effectiveness of a screening program for hepatitis C. Dig Dis Sci 2006, 51:976-981.

82. Rifai MA, Moles JK, Lehman LP, Van der Linden BJ: Hepatitis C screening and treatment outcomes in patients with substance use/dependence disorders. Psychosomatics 2006, 47:112-121.

83. Zuniga IA, Chen JJ, Lane DS, Allmer J, Jimenez-Lucho VE: Analysis of a hepatitis C screening programme for US veterans. Epidemiol Infect 2006, 134:249-257.

84. Alexanian AA, Oleszkiewicz GM, Al-Chalabi T, Atabani S, Muir D, TudorWilliams G, Brown AS: Observational outcomes in a cohort of women identified as hepatitis $\mathrm{C}(\mathrm{HCV})$ antibody positive during routine antenatal clinic (ANC) screening. Abstract for the 60th Annual Meeting of the American Association for the Study of Liver Diseases: The Liver Meeting 2009 Boston, MA United States. Hepatology 2009, 669A

85. Abusheikha N, Akagbosu F, Marcus S, Lass A, Cousins C, Brinsden P: Viral screening and assisted conception treatment-the Bourn Hall experience. J Assist Reprod Genet 1999, 16:337-339.

86. Leikin EL, Reinus JF, Schmell E, Tejani N: Epidemiologic predictors of hepatitis C virus infection in pregnant women. Obstet Gynecol 1994, 84:529-534.

87. Ward C, Tudor-Williams G, Cotzias T, Hargreaves S, Regan L, Foster GR: Prevalence of hepatitis $C$ among pregnant women attending an inner London obstetric department: uptake and acceptability of named antenatal testing. Gut 2000, 47:277-280

88. Costa ZB, Machado GC, Avelino MM, Gomes FC, Macedo Filho JV, Minuzzi AL, Turchi MD, Stefani MM, de Souza WV, Martelli CM: Prevalence and risk factors for Hepatitis C and HIV-1 infections among pregnant women in Central Brazil. BMC Infect Dis 2009, 9:116.

89. Freudenreich O, Gandhi RT, Walsh JP, Henderson DC, Goff DC: Hepatitis C in schizophrenia: screening experience in a community-dwelling clozapine cohort. Psychosomatics 2007, 48:405-411

90. Gunewardene R, Lampe L, Ilchef R: Prevalence of hepatitis C in two inpatient psychiatry populations. Australas Psychiatry 2010, 18:330-334

91. Lacey C, Ellen S, Devlin H, Wright E, Mijch A: Hepatitis C in psychiatry inpatients: testing rates, prevalence and risk behaviours. Australas Psychiatry 2007, 15:315-319.

92. Capron D, Bensousan T, Darchis JP, Barbare JC, Butel J, Bental A, Cadranel JF, Goll A, Levy P, Ink O, Autret P, Bouraya D, Thiebaut JM, Moucheron JJ, Bernard M, Lallement PY, Delobel P: Hepatitis C virus infection risk factors in patients admitted in hospital emergency departments in Picardy. Value of oriented screening based on recommendations of the 'Direction Generale de la Sante'. Eur J Gastroenterol Hepatol 1999, 11:643-648.

93. Alswaidi FM, O'Brien SS: Is there a need to include HIV, HBV and HCV viruses in the Saudi premarital screening programme on the basis of their prevalence and transmission risk factors? J Epidemiol Community Health 2009

94. Dubois F, Francois M, Mariotte N, Caces E, Vol S, Roingeard P, Barin F, Goudeau A, Tichet J: Serum alanine aminotransferase measurement as a guide to selective testing for hepatitis $C$ during medical checkup. $J$ Hepatol 1994, 21:837-841.

95. Roberts J, Cull M, Dean G, Richardson D, Fisher M: Improved but still suboptimal uptake of STI testing and vaccination in the outreach setting. Abstract for the 2 nd Joint Conference of the British HIV Association and the British Association for Sexual Health and HIV Manchester United Kingdom. HIV Med 2010, 118.

96. Cohen DE, Russell CJ, Golub SA, Mayer KH: Prevalence of hepatitis C virus infection among men who have sex with men at a Boston community health center and its association with markers of high-risk behavior. AlDS Patient Care STDS 2006, 20:557-564

97. Campello C, Poli A, Dal MG, Besozzi-Valentini F: Seroprevalence, viremia and genotype distribution of hepatitis $C$ virus: a community-based population study in northern Italy. Infection 2002, 30:7-12. 
98. Tafuri S, Prato R, Martinelli D, Melpignano L, De Palma M, Quarto M, Germinario C: Prevalence of Hepatitis B, C, HIV and syphilis markers among refugees in Bari, Italy. BMC Infect Dis 2010, 10:213.

99. Sahajian F, Vanhems P, Bailly F, Fabry J, Trepo C, Sepetjan M: Screening campaign of hepatitis $C$ among underprivileged people consulting in health centres of Lyon area, France. Eur J Public Health 2007, 17:263-271.

100. Sequist TD, Zaslavsky AM, Marshall R, Fletcher RH, Ayanian JZ: Patient and physician reminders to promote colorectal cancer screening: a randomized controlled trial. Arch Intern Med 2009, 169:364-371.

101. Gollwitzer PM: Implementation Intentions: Strong effects of simple plans. Am Psychol 1999, 54:493-503.

102. Centers for Disease Control and Prevention: Guidelines for laboratory testing and result reporting of antibody to hepatitis C virus. MMWR 2003, 52:(No. RR-3).

103. Grimaudo NJ, Lado E: Hepatitis C screenings available at FNDC. Todays FDA 2000, 12:28-30.

104. Wadley F: H.A.L.T. hepatitis C in Tennessee. Tenn Med 1997, 90:395.

105. Nakamura J, Terajima K, Aoyagi Y, Akazawa K: Cost-effectiveness of the national screening program for hepatitis $C$ virus in the general population and the high-risk groups. Tohoku J Exp Med 2008, 215:33-42.

106. Coffin PO, Scott JD, Golden MR, Sullivan SD: Cost-effectiveness and population outcomes of general population screening for hepatitis $C$. Clin Infect Dis 2012, 54:1259-1271.

107. Rein DB, Smith BD, Wittenborn JS, Lesesne SB, Wagner LD, Roblin DW, Patel N, Ward JW, Weinbaum CM: The cost-effectiveness of birth-cohort screening for hepatitis $\mathrm{C}$ antibody in U.S. primary care settings. Ann Intern Med 2012, 156:263-270

108. Wilson JM, Jungner YG: Principles and practice of mass screening for disease. Bol Oficina Sanit Panam 1968, 65:281-393.

109. Jones L, Bates G, McCoy E, Beynon C, McVeigh J, Bellis M: A Systematic Review of the Effectiveness and Cost-Effectiveness of Interventions Aimed at Raising Awareness and Engaging with Groups who are at an Increased Risk of Hepatitis B and C Infection - Final Report, Centre for Public Health, Faculty of Health and Applied Social Sciences. Liverpool: Liverpool John Moores University; 2012.

110. Smith BD, Morgan RL, Beckett GA, Falck-Ytter Y, Holtzman D, Ward JW: Hepatitis C virus testing of persons born during 1945-1965: recommendations from the Centers for Disease Control and Prevention. Ann Intern Med 2012, 157:817-822.

111. Hayashi J, Kishihara Y, Yamaji K, Yoshimura E, Kawakami Y, Akazawa K, Kashiwagi S: Transmission of hepatitis $C$ virus by health care workers in a rural area of Japan. Am J Gastroenterol 1995, 90:794-799.

112. Kaur S, Rybicki L, Bacon BR, Gollan JL, Rustgi VK, Carey WD: Performance characteristics and results of a large-scale screening program for viral hepatitis and risk factors associated with exposure to viral hepatitis $B$ and C: results of the National Hepatitis Screening Survey. National Hepatitis Surveillance Group. Hepatology 1996, 24:979-986.

113. Bellentani S, Tiribelli C, Saccoccio G, Sodde M, Fratti N, De Martin C, Cristianini G: Prevalence of chronic liver disease in the general population of northern Italy: the Dionysos Study. Hepatology 1994 20:1442-1449

114. Fagundes GD, Bonazza V, Ceretta LB, Back AJ, Bettiol J: Detection of the hepatitis C virus in a population of adults. Rev Lat Am Enfermagem 2008, 16:396-400

115. Batash S, Khaykis I, Raicht RF, Bini EJ: High prevalence of hepatitis C virus infection among immigrants from the former Soviet Union in the New York City metropolitan area: results of a community-based screening program. Am J Gastroenterol 2008, 103:922-927.

116. ARèS 92: Intérêt d'un "parcours santé" proposé aux résidents d'un foyer Sonacotra. BEH 2004, 43:205-206.

117. Goetz AM, Ndimbie OK, Wagener MM, Muder RR: Prevalence of hepatitis C infection in health care workers affiliated with a liver transplant center. Transplant 1995, 59:990-994.

118. Thomas DL, Factor SH, Kelen GD, Washington AS, Taylor E Jr, Quinn TC: Viral hepatitis in health care personnel at The Johns Hopkins Hospital. The seroprevalence of and risk factors for hepatitis B virus and hepatitis C virus infection. Arch Intern Med 1993, 153:1705-1712.

119. Panlilio AL, Shapiro CN, Schable CA, Mendelson MH, Montecalvo MA, Kunches LM, Perry SW 3rd, Edwards JR, Srivastava PU, Culver DH: Serosurvey of human immunodeficiency virus, hepatitis B virus, and hepatitis $C$ virus infection among hospital-based surgeons. Serosurvey Study Group. J Am Coll Surg 1995, 180:16-24.

120. Upfal MJ, Naylor P, Mutchnick MM: Hepatitis C screening and prevalence among urban public safety workers. J Occup Environ Med 2001, 43:402-411.

121. Gershon RR, Vlahov D, Farzadegan H, Alter MJ: Occupational risk of human immunodeficiency virus, hepatitis $B$ virus, and hepatitis $C$ virus infections among funeral service practitioners in Maryland. Infect Control Hosp Epidemiol 1995, 16:194-197.

122. Torda AJ: Vaccination and screening of medical students: results of a student health initiative. Med J Aust 2008, 189:484-486.

123. Arumainayagam J, Grimshaw R, Acharya S, Chandramani S, Morrall IA, Pugh $\mathrm{RN}$ : Value of targeting at-risk populations at outreach venues: Findings from a local sauna. Int J STD AIDS 2009, 20:642-643.

\section{doi:10.1186/1471-2458-14-66}

Cite this article as: Zuure et al:: Outcomes of hepatitis C screening

programs targeted at risk groups hidden in the general population: a systematic review. BMC Public Health 2014 14:66.

\section{Submit your next manuscript to BioMed Central and take full advantage of:}

- Convenient online submission

- Thorough peer review

- No space constraints or color figure charges

- Immediate publication on acceptance

- Inclusion in PubMed, CAS, Scopus and Google Scholar

- Research which is freely available for redistribution 